\title{
The Capital Structure Choice of European Firms: The Role of Financial System and Institutional Setting
}

\author{
Daniela Venanzi $^{1} \&$ Alessia Naccarato ${ }^{1}$ \\ ${ }^{1}$ Department of Economics, Roma Tre University, Rome, Italy \\ Correspondence: Daniela Venanzi, Department of Economics, Roma Tre University, Via Silvio D'Amico 77 - \\ 00145 Rome, Italy.
}

Received: September 26, 2017

doi:10.5539/ibr.v10n12p22
Accepted: October 16, 2017 Online Published: October 27, 2017

URL: https://doi.org/10.5539/ibr.v10n12p22

\begin{abstract}
Recent international financial research finds that a firm's capital structure is not only influenced by firm- and industry-specific determinants, but also by country-specific factors. Starting from the last decade's studies on the country effect and addressing some areas of potential development in empirical testing, we test, on a sample of seven apparently similar European countries and more than 800,000 variously sized firms (from the BACH-ESD database) over a ten year period (2000-2009), the direct effects of country characteristics on leverage, as well as their mediating role on the effects of firm- and industry-specific determinants, by using a simultaneous equation model (SEM) never used before by any scholar in this field. The emerging empirical evidence: $i$ ) highlights the relevance of many institutional, financial, and macroeconomic country characteristics; ii) confirms the better ability of banks in selecting, monitoring, and financing small and risky firms; iii) shows that the demand-side perspective can better explain some counter-intuitive effects of some determinants on leverage.
\end{abstract}

Keywords: capital structure, country characteristics, financial systems, institutional setting, European countries, empirical study

\section{Introduction}

The choice of capital structure is a hot issue in international financial research. Since the Modigliani-Miller (1958) seminal contribution, many theories have been formulated and many empirical studies implemented. However, ample space for further research still remains, since the empirical evidence does not always support the theoretical hypotheses on the determinants of financial leverage, and often stimulates the formulation and testing of new hypotheses.

In this context, the country effect on financial leverage seems to be a good candidate for further analysis. Prior research (e.g., Rajan - Zingales, 1995; Demirguc-Kunt - Maksimovic, 1999; Booth et al., 2001; Giannetti, 2003; Hall et al., 2004; Bancel - Mittoo, 2004; Antoniou et al., 2008; de Jong et al., 2008; Aggarwal - Kyaw, 2009; Alves - Ferreira, 2011; Kayo - Kimura, 2011; Fan et al., 2012; Acedo-Ramirez - Ruiz-Cabestre, 2014) finds that both firm- and industry-specific determinants and country-specific factors influence a firm's capital structure. It also evidences that many country characteristics, such as the macroeconomic context, the institutional framework, and the financial system, affect a firm's capital structure. In addition, the most recent studies demonstrate that country-specific factors can affect corporate leverage not only directly, but also indirectly, i.e. through their impact on the effect of non-country determinants (especially, firm-specific variables).

This paper aims at formulating and empirically testing, on a sample of seven apparently similar European countries and more than 800,000 variously sized firms (from the BACH-ESD database) over a ten year period (2000-2009), an explanatory model of both the cross-sectional and the longitudinal variability of corporate leverage, which evidences the direct effects of country characteristics on leverage, as well as their mediating role on the effects of firm- and industry-specific determinants, by using a simultaneous equation model (SEM), never used before by any scholar in this field. In fact, based on the review of some last decade's studies on country effect and the subsequent identification of some areas of potential development in empirical testing (Venanzi, 2017), we try to address some of these areas of criticism in formulating the model and building our empirical analysis. Therefore, in comparison with the previous studies on country effect, our analysis contributes to the scientific debate with the following original features: 
a) we use a set of countries which is generally assumed to be homogeneous, in terms of type of financial system (all bank-based) and institutional origin (all civil law countries). As shown before, these countries significantly differ in both financial and institutional characteristics, although they are generally considered homogeneous in the empirical studies that adopt a broader set of countries; therefore, using general taxonomies in classifying country and explaining the variance of leverage is likely to underestimate the country effect and tells only a part of the story;

b) we use a large sample of firms, which variously differ in terms of size and industry, including small and non-listed firms, whose financial decisions are more subject to the institutional and financial constraints imposed by their domestic markets (Giannetti, 2003);

c) we use a broad set of determinants, at firm, industry, and country level, breaking down each level in an ample set of variables;

d) we estimate an explanatory model of leverage that fits both the cross-sectional and the longitudinal variability of corporate leverage, and therefore avoids the use of average values of dependent and independent variables over time, as some studies do. Furthermore, we ask our explanatory model to be robust over a range of years that includes different phases of the economic cycle: from the "small crisis" of 2002-2003 to the deep recent crisis of 2008-2009, through the expansion of 2006-2007;

e) we estimate the country's impact on the capital structure choices in terms of both direct and indirect effects, in a model whose parameters are simultaneously estimated. In fact, adopting a simultaneous equation model (SEM), a statistical methodology never used before in this research field, we measure in the same regression model the direct impact of country, industry and firm-specific determinants on corporate leverage in a multi-year framework, as well as the country's indirect effects; the latter are expressed in terms of fully or partially mediated effects of the country characteristics on the impact on leverage of the firm- and industryspecific determinants. In doing so, we avoid the potential bias of a double-step estimation of direct and indirect country effects, generally used in previous studies;

f) we explicitly take into account the Welch (2011) criticism on the measurement of firms' indebtedness, excluding the non-financial liabilities, that are generally related to the specific firm's business and industry characteristics, and are not influenced by the determinants of the capital structure choice, when it represents an explicit managerial decision; in the European countries, these non-financial liabilities (for example the provisions arising from labour market contracts or specific regulations) can have a major weight on the total sources of funds, distorting the measurement of financial leverage, when included (Venanzi, 2010);

g) we use a sample of only bank-based countries: this allows us to realistically measure the financial leverage, considering also the short-term bank debt, which represents a very important portion of financial debt, since it often disguises medium-long term debt by means of the tacit renewal mechanism; in bank-based countries, where corporate bonds are very marginally used as a source of funds, considering only the medium-long term debt implies the omission of most financial liabilities:

h) our sample includes observations at size-class level rather than at firm level. As Myers (1984) and Fisher-Heinkel-Zeckner (1989) claim, transaction costs can explain some temporary deviations of a firm from its optimal capital structure, within an acceptable range of non-adjustment. Therefore, the observed static leverage measures do not approximate the target leverage each year. After verifying the homogeneity of leverage within each size-class, we assume that the size-class averages of the dependent variable can better approximate the yearly target leverage, rather than the values of the individual firms' observations. Furthermore, especially for the small-size firms, the average leverage in their class better reduces the risk that the observed values of leverage could be biased by financial market/system constraints, and therefore not representative of the target levels chosen by the firms.

The empirical findings highlight the relevance of many institutional, financial, and macroeconomic country characteristics. In addition, they confirm the better ability of banks in selecting, monitoring, and financing small and risky firms and show that the demand-side perspective can better explain some counter-intuitive effects of some determinants on leverage.

The paper is organized as follows. Section 2 builds the general framework of the country characteristics usually included in the explanatory model of leverage, and the theoretical rationale underlying their expected impact on capital structure choice, taking in account the areas of useful improvement of the test design. Section 3 describes data, research design, methodology and variables adopted in our empirical analysis, outlining the tested 
hypotheses and the structure of the final model. The results are presented in Section 4 and 5. Section 6 concludes the paper.

\section{The Country Effect on the Corporate Debt-Equity Choice}

\subsection{The Relevant Country Characteristics}

Prior research (e.g., Rajan - Zingales, 1995; Demirguc-Kunt - Maksimovic, 1999; Booth et al., 2001; Giannetti, 2003; Hall et al., 2004; Bancel - Mittoo, 2004; Antoniou et al., 2008; de Jong et al., 2008; Aggarwal - Kyaw, 2009; Alves - Ferreira, 2011; Kayo - Kimura, 2011; Fan et al., 2012; Acedo-Ramirez - Ruiz-Cabestre, 2014) finds that a firm's capital structure is not only influenced by firm- and industry-specific determinants, but also by country-specific factors: many country characteristics, such as the macroeconomic context, the institutional framework and the financial system, seem to affect (directly and indirectly) a firm's capital structure.

The main recent studies adopt a causal determinants-leverage explanatory approach, using samples large and variegate in terms of countries considered, that differ for the development stage of the economy (developed and developing countries), type of financial systems (bank- and market-based), and institutional environments (common and civil law countries, and related law and order frameworks). The country determinants are generally associated with firm-specific determinants (very similar across studies), and more rarely with industry-specific variables (Giannetti 2003; Antoniou et al. 2008 and Kayo-Kimura 2011), often omitted or simply included as industry dummies (fixed industry effect), no matter which characteristics they differ for. The country effect is generally measured including many country characteristics (institutional framework, financial system, and macro-economic scenario) as regressors of the leverage. Only a few studies include in the empirical test the country dummies, omitting a more explicit characterization.

The most frequently used country variables are the following:

a) Financial characteristics

This set of variables mainly refers to the development stage of a country's financial system and concerns the availability of a wider spectrum of sources of funds at a lower cost. Banking system development and bond market development positively influence the firm's leverage; stock market development negatively influences the firm's leverage, because a broader supply of funds and a lower information asymmetry between managers and investors decrease the cost of equity, and therefore determine a higher managers' propensity to issue equity to finance investments. However, the stock market turnover enhances creditors' willingness to lend, thanks to better opportunities to monitor the listed firms, or makes banks' funds more available to non-listed firms. Furthermore, we can consider the financial system structure as a determinant of leverage (de Jong et al., 2008; Kayo-Kimura, 2011), because it has direct implications on the sources of funds available to the corporate sector (Antoniou et al. 2008).

The type of financial system can be related to the degree of ownership concentration of companies: firms in market-based countries have a less concentrated ownership structure, while in bank-based countries the concentration is higher. Assuming that, in an agency perspective, debt plays an important disciplinary role against managers' opportunistic behaviour (Jensen 1986), the firm's leverage is assumed to be higher in market-based countries. However, in bank-oriented countries, banks play a significant role in gathering the information and monitoring management; therefore, we expect better access to external borrowing and, thus, higher debt levels.

The more frequently indirect effects tested are the following:

1. the banking system development (or, simply, its orientation) mitigates the effect of bankruptcy costs on leverage, in terms of business risk, size, and tangibility;

2. the banking system development (or, simply, its orientation) mitigates the effect of agency costs on leverage, in terms of tangibility and growth;

3. the two mediation effects above can be performed by the bond market's development;

4. the stock market's development mitigates the effect of agency costs on leverage, in terms of tangibility and growth.

The expected sign of the impact of some determinants of leverage can be different, depending on the prevalence of the supply-side vs. the demand-side perspective. For example, the creditor's rights protection (discussed below) might positively affect leverage because lenders are likely to be more willing to supply financing, but, on the other hand, the impact can be negative if we assume a demand-side perspective: firms will be more reluctant to borrow, fearing higher distress costs. 
b) Institutional characteristics

All studies recognize the important role of the country's institutional characteristics in influencing corporate decisions on capital structure, although the impact of these variables, in general, is not so evident. These determinants derive from La Porta et al. (1998) approach, which assumes that the type of legal system (common versus civil law countries) affects both the content of the laws and the quality of their enforcement, and therefore the extent of legal protection of external investors. Since the conflicts of interest between corporate insiders (managers and/or majority shareholders) and external investors (minority shareholders and creditors) are important factors that influence the corporate financial structure (according with the agency approach), the extent to which contracts can be used to mitigate these incentive problems depends on the legal system and enforceability of these contracts. The type of legal system is generally broken into a set of institutional characteristics, such as creditors' right protection, shareholders' right protection (anti-director rights), quality of laws and regulations, and promptness of their enforcement.

The corruption index proxies for the threat of investors' rights expropriation by managers or public officers. Debt is expected to be used relatively more than equity when the public sector is more corrupt, since it is easier to expropriate outside equity holders than debt holders. The enforcement of debt contracts or the presence/absence of an explicit bankruptcy code that regulates the resolution of default (Djankov et al. 2007; Fan et al. 2012) affect the firm's leverage: poorly defined bankruptcy procedures and longer period to enforce a debt contract reduce the lenders' bargaining power against the borrowers, and therefore discourage the use of debt or make it more costly.

c) Macroeconomic characteristics

These country variables are less frequently used than others, or used more often as control variables. Among these variables, inflation rate and inflation rate volatility are the most widely used regressors of leverage. Investors would be less willing to lend if they are not sure about the real returns on their loans, i.e., if they face higher inflationary risk. On the other hand, if interest rates do not appropriately reflect the inflation rate, inflation can be associated with higher debt levels, since the real repayment value of debt declines with inflation. Inflation uncertainty increases the firm's business risk through volatility in the firm's selling prices, costs, and volume of sales; therefore, in a highly inflationary country with high inflation uncertainty, firms will experience high business risk and carry less debt in their capital structure.

As stated by Demirguc-Kunt and Maksimovic (1999), annual growth rate in national GDP is an indicator of the financing needs of firms, that triggers a positive effect on the use of debt. Capital formation can affect corporate leverage both positively and negatively: the accumulation of more retained earnings induces less dependence on debt usage, assuming the $\mathrm{POH}$ perspective; however, it could also generate more financial needs and therefore a higher need to use external sources of funds, i.e. more debt.

The tax system in general, and specifically the tax treatment of interest and dividend payments, has been recognized as an important factor influencing capital structure choices since the seminal work of Modigliani and Miller (1958). Some studies (Booth et al. 2001; Fan et al. 2012) include this determinant at the country level, rather than at the firm level. They use the country's statutory tax rate or the relative tax advantage of debt, considering both corporate and personal tax rates according to Miller's (1977) formulation, or, alternatively, the tax treatment of dividend, distinguishing between countries with dividend imputation or tax relief systems, on the one hand, and countries with classical tax systems, that double-tax corporate profits, on the other hand: in the latter, firms are expected to use more debt than in the former.

\section{Research Design, Data, and Variables}

\subsection{Test Design and Data}

The empirical test conducted in this paper differs from the international studies about the country effect on the capital structure choice in many aspects, discussed below (following the criticisms highlighted in Venanzi, 2017).

1) Firstly, we use a relatively homogeneous set of countries, in terms of type of financial system - all bank-based- and institutional origin: all civil law countries, of French (Belgium, France, Italy, Spain and Portugal) or German derivation (Austria and Germany). The objective is to show that distinguishing countries along these general taxonomies is not appropriate for measuring the country effect on the corporate capital structure choice. These countries differ in both the financial and the institutional variables in a statistically significant way (see Venanzi, 2017), although they are generally considered homogeneous in the empirical studies where an ampler set of countries is adopted. Therefore, the empirical evidence emerging from the studies that use these general taxonomies as country determinants of leverage, underestimates the country effect and tells only a part of the story. Furthermore, considering only countries 
operating in the same monetary system (European Union) contributes to focus the country effect measurement on the explanatory variables included in the regression model, limiting the risk that the effect of these macro-context differentials could distort the financial and institutional determinants' impact, especially when a larger sample of countries is used and controlling them is likely to be impossible.

2) Secondly, we use a large sample of firms (about 800.000), over a ten-year period (2000-2009). The core set of data derives from the Bank for the Accounts of Companies Harmonized (BACH) and the European Sectoral References Database (ESD) projects (BACH-ESD) (managed by Banque de France). Firms' data are aggregated into three size-classes, defined in terms of turnover: class 1 includes firms with less than 10 million euros of revenues (small firms), class 2 includes those between 10 and 50 million of revenues (medium-sized firms), and class 3 includes those with more than 50 million euros of revenues (large firms). The firms belong to 23 industries of the secondary and tertiary sectors, following the NACE (Nomenclature statistique des activités économiques dans la Communauté européenne) classification: 15 manufacturing industries, 3 energy, water supply and construction industries, 3 wholesale and retail trade industries, and 2 service industries (transportation and accommodation, and food services). The objective is to build an explanatory model of capital structure, which could be tested on a diversified set of firms and include a large set of determinants. Furthermore, our explanatory model should be robust over a range of years that includes different phases of the economic cycle: from the "small crisis" of 2002-2003 to the deep recent crisis of 2008-2009, through the expansion of 2006-2007.

Our sample also includes small and non-listed firms: this strengthens the model generalizability and the significance of the results; in many of the countries included in the sample, large listed firms just represent a minor share of their countries' GDP and a small proportion of the existing firms. Tentatively, this allows to better highlight the country effect, that could be obscured by samples only made of listed firms, whose financial decisions are less subject to the institutional and financial constraints imposed by their domestic markets.

Due to the open nature of the sample, the number of firms in each size-class or industry can vary over the years. The BACH-ESD dataset includes data only if the number of firms in each size-class is larger than 5 . To strengthen the analysis, the extracted sample excludes all the cases that present serial missing values. Furthermore, to avoid biased results, we built a balanced pattern of data: the number of observations in the sample for each country, industry and year is the same. Therefore, all the industries and countries that showed serial missing data were excluded. The final sample includes 4,830 observations: 690 for each country, 210 for each industry, 483 for each year, and 1,610 for each size-class.

3) Thirdly, our sample includes observations at size-class level rather than at firm level. After verifying the homogeneity of leverage within each size-class, the yearly size-class averages of the dependent variable can better approximate the target leverage than the values observed at the individual firms' level. As Myers (1984) and Fisher-Heinkel-Zeckner (1989) claim, transaction costs can explain some temporary deviations of a firm from its optimal capital structure, within an acceptable range of non-adjustment. Therefore, the observed static leverage measures do not approximate the target leverage each year. Furthermore, an open sample over time (in which the sample firms change year by year), while does not permit to test a dynamic adjustment model toward target [the BACH-ESD database also provides data for sliding samples, but the evidence emerging from Leary-Roberts (2005), Lemmon et al. (2008), Flannery-Rangan (2006), Hovakimian et al. (2001) and Hovakimian (2004), shows that the target adjustment process is neither linear nor on a yearly basis], could allow a more robust measure of the target leverage at the size-class level, thanks to an ampler and varying sample. In addition, especially for the small size firms, the average leverage in their class better smooths the risk that the observed values of leverage could be biased by financial market/system constraints and therefore be not representative of the target levels chosen by the firms.

The relative homogeneity of the dependent variable (i.e. the financial leverage) within each size class is tested by measuring how much of the dispersion across firms of a certain country-industry-year combination is attributable to the within size class variability. We use the interquartile coefficients for measuring variability ${ }^{1}$, weighting them by the number of firms. We obtain an average value of $35 \%$ for four of the ratios used in calculating the financial leverage and an average value of $52 \%$ for the fifth ratio (long

\footnotetext{
${ }^{1}$ The BACH-ESD database provides average, median, first and third quartiles for all the ratios.
} 
term debt on total assets ratio) and a median value of about $20 \%$. This means that most part of variability of the financial leverage across firms, in each country-industry-year combination, depends on size.

4) Fourthly, we estimate the country's impact on the capital structure choice in terms of both direct and indirect effects in a model whose parameters are simultaneously estimated, including those related to the firm and industry-specific determinants. In fact, adopting a simultaneous equation model (SEM), a statistical methodology never used before in this research field, we simultaneously measure (i.e. in the same regression model) the direct impact of country, industry and firm specific determinants on corporate leverage in a multi-year framework, as well as the country's indirect effects: these are explicated as fully or partially mediated effects that the country characteristics play on the impact on leverage of the firm- and industry- specific determinants. In doing so, we prevent the potential bias that can derive from an approach (used in many studies) that adopts a double step estimation of direct and indirect country effects: this approach $e x$ ante assumes that the country indirect effect exists and therefore estimates separate regressions by country (or by other predefined subsamples of countries), hence regressing in a second regression the coefficients of the firm and industry determinants on the country's characteristics. Giannetti (2003) and Kayo-Kimura (2011) use a similar approach, but they use a cross-sectional approach and interaction variables instead of fully or partially mediated effects (see section 3.3 below).

Table 1. Dependent and independent variables

\begin{tabular}{|c|c|}
\hline Variable & Measurement \\
\hline \multicolumn{2}{|l|}{ dependent variable } \\
\hline LEV & financial debts/(financial debts + equity) \\
\hline \multicolumn{2}{|l|}{ Size - specific } \\
\hline ROA & $\begin{array}{l}\text { EBIT/invested capital (net of pension funds and trade } \\
\text { credit and financial assets) }\end{array}$ \\
\hline TANG & tangible fixed assets/total assets \\
\hline LIQ1 & current assets/total assets \\
\hline LIQ2 & cash \& cash equivalents/total assets \\
\hline OPRISK & fixed costs/total costs \\
\hline NDTS & depreciation/net turnover \\
\hline @1 -@2-@3 & $\begin{array}{l}1 \text { if the observation belongs to the size-class, } 0 \text { otherwise. } \\
\text { (a) } 1=\text { small }(<10 \mathrm{ml} € \text { turnover }) \text {; } 2=\text { medium }(10-50 \mathrm{ml} \\
€) ; \text { a } 3=\text { large }>50 \mathrm{ml} €)\end{array}$ \\
\hline \multicolumn{2}{|l|}{ Industry - specific } \\
\hline BUSRISK & $\begin{array}{l}\text { interquartile distance of ROS (EBIT/total assets) at } \\
\text { industry level }\end{array}$ \\
\hline$\%$ EBIT & $\begin{array}{l}\text { EBIT/net turnover } \\
\text { (all size-classes) }\end{array}$ \\
\hline $\mathrm{HH}$ & $\begin{array}{c}\sum_{i=1}^{100} s_{i}^{2} \\
\text { (where } \mathrm{s}_{\mathrm{i}}^{2} \text { measures the square of the market share of the } \\
\text { firm } \mathrm{i} \text {, calculated on the total turnover of the BACH } \\
\text { sample) }\end{array}$ \\
\hline MANUFACT & $\begin{array}{c}1 \text { if the observation belongs to } \mathrm{NACE} \text { sectors } \mathrm{C} \\
\text { (manufacturing), } 0 \text { if belongs to sectors from } \mathrm{D} \text { to I } \\
\text { (services). }\end{array}$ \\
\hline
\end{tabular}

Country-specific (time-invariant)

SHARIGHTS

aggregate score of shareholder rights (by adding one when shareholder rights - such as proxy vote by mail, cumulative voting or proportional representation of minorities, etc... - are guaranteed) ranges from 0 (the weakest) to 6 (the strongest) 


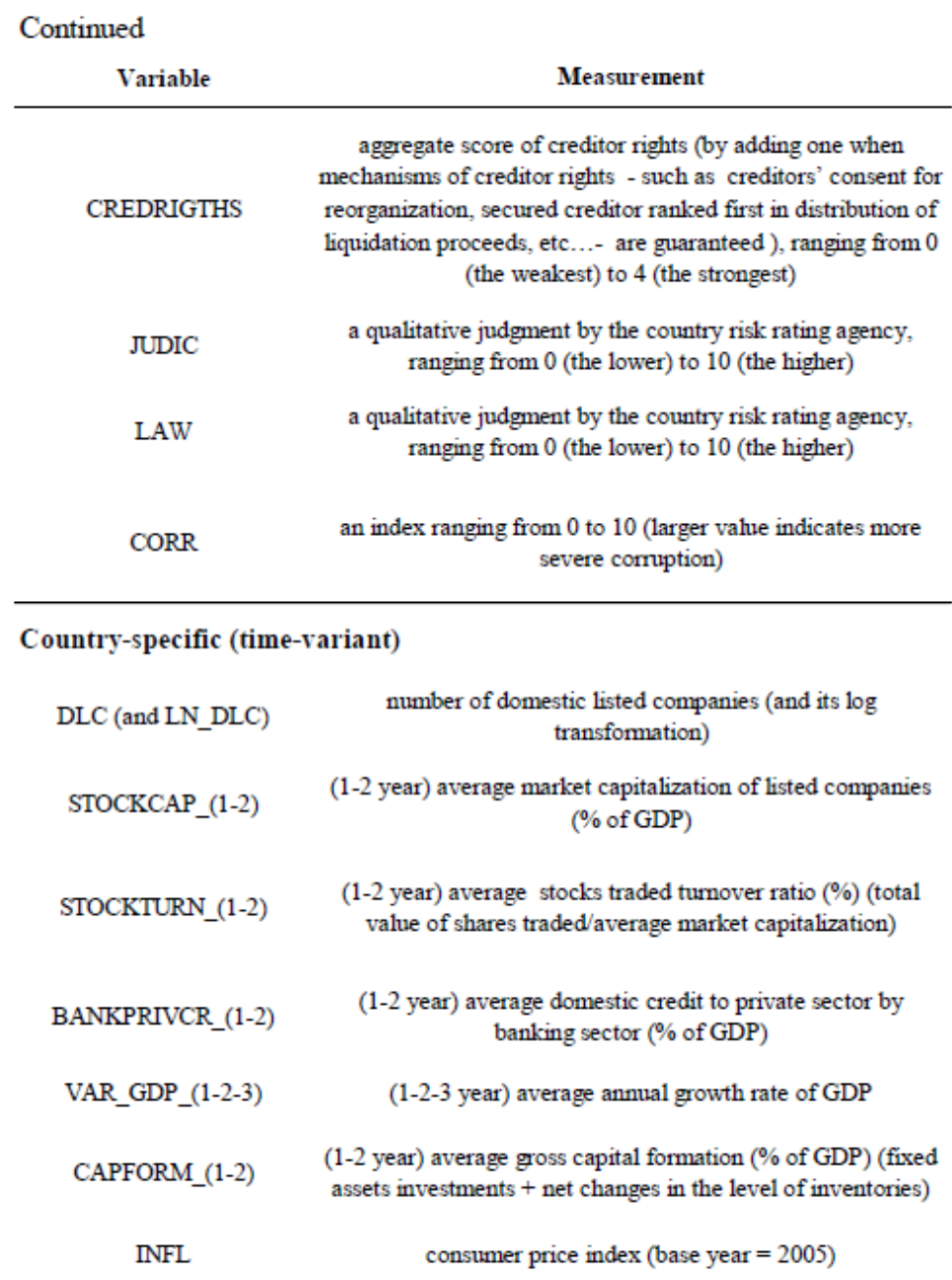

Comparing firm-level accounting data across countries is not exempt from comparability limitations: the harmonization in accounting standards and practices pursued by the BACH-ESD dataset is likely to greatly guarantee the comparability of data, since this is considered its main objective and is implemented at an institutional level; in fact, the project involves the Central Banks of the participating countries and was developed in close co-operation with the European of Central Balance Sheet Data Offices.

\subsection{The Variables}

Table 1 summarizes the dependent and independent variables used in the empirical test (the latter are the most significant measures of leverage determinants, selected among a large set of tested proxies). We briefly discuss them in the following sections.

\subsubsection{The Dependent Variable}

According to Welch (2011), we measure leverage only referring to the interest-bearing debt, because we want to identify the variables that influence the explicit financing choice of a certain corporate capital structure.

We include both short term and long term financial debt, because our sample includes bank-based countries, in which bank short term debt often disguises medium-long term debt, by means of the tacit renewal mechanism, and therefore heavily weights on total financial debt (D_MAT in Table 2 measures the incidence of bank short term loans on total bank loans). The measure adopted for estimating leverage is not neutral, as Table 2 clearly shows. In fact, although financial leverage and total leverage are strongly correlated, we can see that they importantly differ in terms of mean and degree of variability (total leverage is more stable than financial leverage $)^{2}$.

\footnotetext{
${ }^{2}$ Note that all the variances are underestimated, since they are calculated on aggre gated data, i.e. size-class - industry - year combinations.
} 
Furthermore, the proportion of short term debt is very important (it ranges from one third in Belgium to about two thirds in Italy) and cannot be ignored in analysing the capital structure choice of the European firms. However, the short-term debt component is often omitted to avoid its excessive time variability, since it is more flexible and better suited in matching the unexpected changes of financial needs (Shyam-Sunder and Myers, 1999). In our study, howe ver, using the size-class average rather than the individual firm observation, we smooth this effect, while maintaining the stable component of short term debt.

We use book leverage instead of market leverage because we use a larger sample, including not listed companies.

\subsubsection{The Independent Variables}

We organize the independent variables in three categories, referring to the three macro-determinants of financial leverage (firm, industry, and country), whose characteristics they approximate. As said above, we limited the use of dummies, preferring to breakdown country, industry, and firm effects through their respective characteristics.

We included the year dummies as time fixed effects: however, as discussed above, in our test design the effect of time is likely to be absorbed by the time-variant determinants considered in the analysis, that belong to the three categories. We prefer to avoid considering time as an independent explanatory determinant such as country- or industry- or firm- specific determinants (as for example in Kayo-Kimura 2011), but explicitly assuming and tentatively explaining the longitudinal pattern of the analysed phenomenon.

Table 2. Leverage measures (\%) (2000-2009)

Averages and coefficients of variation are calculated on aggregate data - size class $\times$ industry $\times$ year - , no matter their case number. TOTLEV measures the total indebtedness (ratio of difference between total assets and capital \& reserves to total assets). D_MAT measures the debt maturity (ratio of short term bank debts to bank debts).

\begin{tabular}{|c|c|c|c|c|c|c|c|}
\hline \multirow{2}{*}{ country } & \multirow{2}{*}{ size class } & \multicolumn{2}{|c|}{ LEV } & \multicolumn{2}{|c|}{ TOTLEV } & \multicolumn{2}{|c|}{ D_MAT } \\
\hline & & average & $\mathrm{SD} /$ average & average & $\mathrm{SD} /$ average & average & $\mathrm{SD} /$ average \\
\hline \multirow{3}{*}{ AUSTRIA } & LARGE & 55.18 & 0.27 & 65.71 & 0.18 & 58.16 & 0.28 \\
\hline & MEDIUM & 54.21 & 0.21 & 63.95 & 0.15 & 54.76 & 0.30 \\
\hline & SMALI & 68.44 & 0.18 & 74.63 & 0.14 & 50.14 & 0.27 \\
\hline \multirow{3}{*}{ BELGIUM } & LARGE & 50.54 & 0.25 & 61.79 & 0.18 & 50.89 & 0.52 \\
\hline & MEDIUM & 48.20 & 0.21 & 59.47 & 0.17 & 45.37 & 0.44 \\
\hline & SMALL & 49.59 & 0.30 & 58.19 & 0.23 & 33.47 & 0.45 \\
\hline \multirow{3}{*}{ FRANCE } & LARGE & 54.83 & 0.22 & 67.08 & 0.17 & 43.45 & 0.50 \\
\hline & MEDIUM & 52.12 & 0.17 & 65.38 & 0.11 & 44.55 & 0.48 \\
\hline & SMALL & 50.02 & 0.19 & 62.69 & 0.13 & 37.93 & 0.51 \\
\hline \multirow{3}{*}{ GERMANY } & LARGE & 55.15 & 0.18 & 68.81 & 0.10 & 45.37 & 0.39 \\
\hline & MEDIUM & 57.93 & 0.16 & 68.73 & 0.11 & 50.86 & 0.34 \\
\hline & SMALI & 64.40 & 0.15 & 73.50 & 0.10 & 47.55 & 0.28 \\
\hline \multirow{3}{*}{ ITALY } & LARGE & 55.09 & 0.15 & 69.46 & 0.11 & 57.64 & 0.27 \\
\hline & MEDIUM & 57.19 & 0.12 & 70.85 & 0.08 & 64.55 & 0.21 \\
\hline & SMALI & 59.19 & 0.13 & 71.79 & 0.10 & 63.20 & 0.23 \\
\hline \multirow{3}{*}{ PORTUGAL } & LARGE & 48.28 & 0.33 & 61.44 & 0.21 & 53.16 & 0.51 \\
\hline & MEDIUM & 51.80 & 0.22 & 64.00 & 0.14 & 55.21 & 0.35 \\
\hline & SMALL & 60.21 & 0.16 & 69.78 & 0.11 & 52.17 & 0.30 \\
\hline \multirow{3}{*}{$\mathrm{SPAIN}$} & LARGE & 44.94 & 0.21 & 59.19 & 0.15 & 48.54 & 0.49 \\
\hline & MEDIUM & 43.52 & 0.23 & 55.03 & 0.17 & 55.81 & 0.31 \\
\hline & SMAIL & 52.36 & 0.10 & 61.65 & 0.08 & 48.55 & 0.29 \\
\hline
\end{tabular}

a) Size class (firm)-specific

As discussed above, our observations are considered at size-class level instead of at firm's level. We include the most common firm-specific determinants considered in the international empirical literature on capital structure choices: we simply measure them as size-class averages, for each country-industry-year combination. 
As far as the firm-level determinants of leverage are concerned, three main theoretical approaches are relevant: the trade-off, the agency, and the pecking order hypotheses, the latter being based on both the Myers-Majluf (1984) information asymmetries theory and the Donaldson (1961 and 1984) managerial and stewardship approaches.

These theories, born as developments of Modigliani and Miller's (1958) approach of a perfect market, suggest that, when we include in the analysis market imperfections, several firm characteristics may determine firm's leverage; these theories often propose the same firm determinants, but the expected effects on financial leverage and the related rationales might change, depending on the adopted theoretical lens. We therefore analyse six firm-level determinants of capital structure: profitability, risk, taxes, liquidity, tangibility, and size.

There is no consensus among the various theories on the influence on capital structure of these firm-specific determinants. For brevity, we avoid discussing here the effect on leverage of the above firm-specific determinants and the related rationale according to the different theoretical perspectives: we refer to the well-developed theories on this field.

The firm-specific determinants are included in the analysis both in absolute and in industry-relative terms, the latter being measured as ratios between the size-class value of the variable and the related industry average. By means of these industry-relative variables, we consider the firm's position within its industry; previous studies (MacKay-Phillips 2005) provided evidence that the financial leverage variation arises more within industries rather than between industries: therefore, we assume that the firm-specific determinants affect leverage not only as absolute measures, but rather when compared to their industry average. It is important to note that all calculations are based on data of firms included in the BACH-ESD sample, which does not represent all the participants in each industry.

b) Industry-specific

Many studies on capital structure employ dummy variables to control the industry effect on leverage. We include in our model only the manufacturing dummy (MANUFACT), that distinguishes manufacturing firms from tertiary sector firms. In fact, we prefer to detail the time-variant characteristics of each industry, following the Kayo-Kimura's (2011) approach and previous studies in the strategy field (Simerly-Li, 2000; Ferri-Jones 1979; Dess-Beard 1984; MacKay-Phillips, 2005), that rationalize the industry characteristics influencing leverage.

Specifically, we include munificence, dynamism, business risk, and firms' concentration of an industry.

Munificence is the environment's capacity to support a sustained growth. Industries with high munificence have abundant resources, low levels of competition and, therefore, we can suppose that companies operating in munificent industries tend to have high levels of profitability.

If we extend the predictions regarding the impact of firms' profitability on leverage to an aggregate industry, we cannot expect an a priori relationship between industry munificence and leverage. As known, in fact, the pecking order theory recognizes a negative relationship between profitability and le verage, whereas the trade-off theory demonstrates a positive one. Therefore, we try to test both signs of the relationship.

We measure munificence by means of the average industry return on sales (\%EBIT).

Dynamism reflects the degree of instability or non-predictable change in an industry (Boyd 1995). Therefore, we assume that firms operating in more dynamic and less predictable environments have lower levels of debt. We measure industry dynamism with the industry cross-sectional dispersion of ROS (BUSRISK), measured as interquartile distance, standardized by the median.

Lastly, we consider the influence of industry concentration on firm leverage using the well-known HerfindahlHirschman (HH) index. Previous studies do not show a univocal sign of the relationship between industry concentration and financial leverage. Some studies (MacKay-Phillips 2005; Lyandres 2001) show that firms in concentrated industries cluster around higher leverage levels, whereas firms in competitive industries carry less leverage and are more widely dispersed. On the contrary, Lipson (1993) predicts lower intra-industry dispersion but lower levels of leverage for concentrated industries. However, the degree of concentration also influences the real-side variables and therefore leverage through them. Competitive industries exhibit greater risk levels and more dispersion in risk. Profitability and asset size are both higher for concentrated industries. These findings suggest that concentrated industries are collusive, exhibiting higher and more stable profitability and less dispersion in profitability than competitive industries (MacKay-Phillips 2005). Product-market competition is less aggressive when leading firms have high financial leverage (Phillips 1995; Kovenock-Phillips 1997). Therefore, the HH effect on leverage is uncertain, since it passes through size, profitability, and risk effects. In this paper, the $\mathrm{HH}$ index is defined as the sum of the squares of market shares of the largest one hundred firms 
within a given industry. The market share of a firm is given by the ratio of its sales to the total sales in the industry.

c) Country-specific

Following the empirical literature on the country effect on leverage, discussed in section 2 above, we detail the country effect including in the regression model time-invariant and time-variant country-specific determinants. Here we only describe the independent variables used in the empirical test, without repeating the theoretical rationales and the empirical evidence underlying them, previously discussed.

As for the time-invariant characteristics, we follow the approach of La Porta et al. (1998). We measure the degree of protection of shareholders' and creditors' rights, as recently reviewed by Spamann (2010) and Djankov et al. (2007): SHARIGHTS and CREDRIGHTS, respectively. Analogously, we include the variables that measure the quality of laws and regulations and the promptness of their enforcement: since conflicts of interest between corporate insiders (managers and/or majority shareholders) and external investors (minority shareholders and creditors) are important factors that influence the corporate financial structure, the extent to which contracts can be used to mitigate these incentive problems depends on these variables. JUDIC measures the efficiency and integrity of the judicial system, LAW assesses the law and order tradition of a country, CORR (Fan et al. 2012) measures the degree of government corruption. We omit the country dummies, since the time-invariant characteristics better represent country fixed effects.

As for the time-variant characteristics, we measure the development of both the stock market and the bank system, as well as some macroeconomics aspects.

We expect that the more developed and liquid is the equity market, the lower is the information asymmetry between investors and insiders (managers or majority shareholders) and the higher the firms' propensity to issue equity to finance investments, lowering debt levels. We measure the stock market development considering both capitalization (STOCKCAP) and turnover (STOCKTURN) ratios, together with the size of stock exchange list (DLC and its log transformation LN_DLC). However, stock market's liquidity and size positively influence the borrowers' transparency and therefore firms' financial leverage.

A country's orientation to banks as a source of finance affects a firm's capital structure choices (Demirguc-Kunt - Maksimovic, 1999). In some countries, like Germany and Italy, banks do not just provide loans, but play a significant role in information gathering and monitoring. Therefore, a highly developed banking sector favours a better access to external borrowing and, thus, higher debt levels. We measure the banking sector de velopment with the ratio of private credit to total bank credit (BANKPRIVCR).

As discussed above, we omit the classification of countries based on general taxonomies such as civil versus common law countries or bank-based versus market-based financial systems. In fact, the countries included in our sample significantly differ from each other, although classified as civil law countries and bank-based systems.

Finally, as far as the macroeconomic characteristics are concerned, we include:

- the country economic growth (VAR_GDP) as proxy of the financing needs of firms (Demirguc-Kunt Maksimovic 1999) at country level: a positive effect of this variable on financial leverage is expected;

- $\quad$ inflation rate (INFL). From a supply-side perspective, in a highly inflationary country, investors will be less willing to lend, since they are not sure about the real returns on their loans; however, from a demand-side perspective, if interest rates do not adequately reflect the high inflation rate, inflation can be associated with higher debt levels because the real repayment value of debt declines with inflation. Inflation uncertainty increases the firm's business risk and will carry less debt in the capital structure;

- capital accumulation (CAPFORM) influences leverage both positively and negatively, depending on whether it refers to financial needs or retained earnings.

Macroeconomic data are obtained from the World Bank and International Monetary Fund websites.

We include for some variables the lagged values, for considering their delayed effects on leverage (the suffix _ 1 or _ 2 is added to the variable name to show the corresponding lagged values).

\subsection{Hypotheses and Methodology}

\subsubsection{The Tested Hypotheses}

We summarize our tested hypotheses in Table 3, articulated by the main categories of determinants: firm-, industry (sector)- and country-specific (F, S, and C hypotheses, respectively). For brevity, we discuss here only 
the hypotheses regarding both the direct and indirect country effects, according to the theoretical and empirical framework outlined in section 2 above, while we refer to section 3.2 for the rationales underlying the hypotheses regarding industry- specific effects and to the wide-spread international literature as far as the firm-specific determinants are concerned. However, we discuss here the indirect firm and industry effects, when country determinants mediate them.

In formulating hypotheses, we use D and I to identify, respectively, the direct effect on financial leverage and the indirect one, i.e. the effect of an independent variable mediated by another variable.

In less developed stock markets there is less information about firms for many reasons such as market illiquidity, weaker regulations, and lower corporate governance standards. This implies more information asymmetries among investors and insiders, raising the cost of capital. For this reason, the stock market development, in terms of both size and liquidity, has a negative impact on financial leverage. However, we could assume a positive effect on financial leverage of both liquidity and size of stock exchanges, since the market liquidity and the size of stock exchange improve firms' transparency from the lenders' standpoint and this effect can be enhanced when the country's judicial and law framework is tight.

\section{C-Hypothesis D1: The stock market development has a negative direct effect on leverage.}

C-Hypothesis I1: The stock market's liquidity and size (in terms of number of listed firms) have a positive indirect effect on leverage, mediated by the law and judicial environment.

The bank sector development positively influences leverage, since firms have more borrowing options, there are more competition among banks, lower costs of funding and higher bank efficiency on choosing borrowers, reducing the adverse selection.

\section{C-Hypothesis D2: The bank sector development has a positive direct effect on leverage.}

The bank market development may also mediate the effects on leverage of some industry characteristics. Specifically, we assume that it mediates the industry dynamism and the concentration effects on leverage. In addition to the expected direct effect (negative for the first factor and both negative and positive for the second), the indirect effect of these two characteristics, mediated by the bank sector development, should be positive. This because in a more developed bank system, banks are more efficient at monitoring, with larger portfolios and better alternatives for diversifying: in this context, a more dynamic industry may be perceived as an opportunity rather than a risk, and more credit will be lent. Analogously, the presence of a more developed bank sector mitigates the negative direct impact on leverage of more competitive industries versus more concentrated ones, lessening the perceived risk that competition induces.

S-Hypothesis I2: The industry dynamism, mediated by the bank sector development, has a positive indirect effect on leverage, i.e. the bank sector development mediates the negative effect of industry dynamism on leverage, reducing it.

S-Hypothesis 13: The industry concentration, mediated by the bank sector development, has a negative indirect effect on leverage, i.e. the bank sector development mediates the positive effect of industry concentration on leverage, reducing it.

The degree of protection of investors, both creditors and shareholders, influences the capital structure choices, as discussed before. When we assume a supply-side perspective, we can formulate the following hypotheses:

C-Hypothesis D3_a: The creditors' rights protection has a positive direct effect on leverage.

C-Hypothesis D4_a: The shareholders'rights protection has a negative direct effect on leverage.

However, when we assume a demand-side perspective, better creditors' rights protection means higher cost of distress and bankruptcy for the borrowers, that should be more severely punished if they do not fulfil their debt obligations. In this scenario, firms might ask for less debt, discouraged by higher "actual" default costs. Analogously, when the agent-principal problem is less important, firms might use more debt, since the diversified shareholders' interests in benefiting from tax shields overtakes the risk-reducing perspective of managers/majority shareholders; in addition, as far as closely held companies are concerned, if investors are more protected, control aversion makes the majority shareholders prefer debt to equity.

$C$-Hypothesis D3_b: The creditors' rights protection has a negative direct effect on leverage.

$C$-Hypothesis D4_b: The shareholders'rights protection has a positive direct effect on leverage.

When analysing the protection of investors' rights, it is important to consider the mediation effect of the judicial context, that can enforce a tighter or weaker protection by the law system. A better judicial system means faster 
sentences, impartial and independent judges, and lower lawsuit costs. Therefore, we assume a positive direct effect on leverage of this variable (quality of the judicial system), assuming the mandatory nature of debt contracts and the residual nature of shareholders' claims. Furthermore, we assume that the quality of the judicial system moderates the degree of protection of investors' rights (we call this "actual" investor - shareholder or creditor - protection), enhancing the related direct effects on leverage, discussed above.

C-Hypothesis D5: The quality of the judicial system has a positive direct effect on leverage.

C-Hypothesis I2: The quality of the judicial system enhances the direct effect of creditors' rights protection on leverage, irrespective of the sign of the relationship.

Table 3. The tested hypotheses

\begin{tabular}{|c|c|c|c|}
\hline \multicolumn{4}{|c|}{ FIRM-SPECIFIC (F-Hypotheses) } \\
\hline \multicolumn{2}{|r|}{ direct effects } & \multicolumn{2}{|r|}{ indirect effects } \\
\hline D1_a & Profitability has a positive direct effect on leverage & & $\begin{array}{l}\text { NDTS, mediated by profitability, has a positive indirect } \\
\text { effect on leverage }\end{array}$ \\
\hline$D 1 \_b$ & Profitability has a negative direct effect on leverage & $I 2$ & $\begin{array}{l}\text { Operating risk, mediated by creditors' rights protection, } \\
\text { has a positive indirect effect on leverage }\end{array}$ \\
\hline D2 & $\begin{array}{l}\text { Non-debt tax shield has a negative direct effect on } \\
\text { leverage }\end{array}$ & 13 & $\begin{array}{l}\text { Asset tangibility, mediated by creditors' rights protection, } \\
\text { has a negative indirect effect on leverage }\end{array}$ \\
\hline D3 & Tangibility has a positive direct effect on leverage & & \\
\hline D4 & Operating risk has a negative direct effect on leverage & & \\
\hline D5 & Operating risk has a positive direct effect on leverage & & \\
\hline D6 & Liquidity has a negative direct effect on leverage & & \\
\hline D7 & Current asset ratio has a positive direct effect on leverage & & \\
\hline D8_a & Firm size has a positive direct effect on leverage & & \\
\hline$D 8 \_b$ & Firm size has a negative direct effect on leverage & & \\
\hline \multicolumn{4}{|c|}{$\begin{array}{l}\text { INDUSTRY (SECTOR) - SPECIFIC (S-Hypotheses) } \\
\end{array}$} \\
\hline & direct effects & & indirect effects \\
\hline D1 & $\begin{array}{l}\text { Industry munificence has a positive direct effect on } \\
\text { leverage }\end{array}$ & & $\begin{array}{l}\text { Industry munificence, mediated by profitability, has a } \\
\text { negative indirect effect on leverage }\end{array}$ \\
\hline D2 & $\begin{array}{l}\text { Industry dynamism has a negative direct effect on } \\
\text { leverage }\end{array}$ & $I 2$ & $\begin{array}{l}\text { Industry dynamism, mediated by bank sector } \\
\text { development, has a positive indirect effect on leverage }\end{array}$ \\
\hline D3_a & $\begin{array}{l}\text { Industry concentration has a positive direct effect on } \\
\text { leverage }\end{array}$ & 13 & $\begin{array}{l}\text { Industry concentration, mediated by bank sector } \\
\text { development, has a negative indirect effect on leverage }\end{array}$ \\
\hline$D 3 \_b$ & $\begin{array}{l}\text { Industry concentration has a negative direct effect on } \\
\text { leverage }\end{array}$ & & \\
\hline D4 & $\begin{array}{l}\text { Manufacturing firms are less leveraged than firms in } \\
\text { tertiary industries }\end{array}$ & & \\
\hline \multicolumn{4}{|c|}{ COUNTRY- SPECIFIC (C-Hypotheses) } \\
\hline & direct effects & & indirect effects \\
\hline Dl & $\begin{array}{l}\text { Stock market development has a negative direct effect on } \\
\text { leverage }\end{array}$ & II & $\begin{array}{l}\text { Stock market's liquidity and size, mediated by law and } \\
\text { judicial environment, have a positive indirect effect on } \\
\text { leverage }\end{array}$ \\
\hline D2 & $\begin{array}{l}\text { Bank sector development has a positive direct effect on } \\
\text { leverage }\end{array}$ & $I 2$ & $\begin{array}{l}\text { The quality of the judicial system enhances the direct } \\
\text { effect of creditors' rights protection on leverage }\end{array}$ \\
\hline D3_a & $\begin{array}{l}\text { Creditors' rights protection has a positive direct effect on } \\
\text { leverage }\end{array}$ & 13 & $\begin{array}{l}\text { The quality of the judicial system enforces the effect of } \\
\text { shareholders' rights protection on leverage } \\
\text { Both the quality of the judicial system and the investors' }\end{array}$ \\
\hline D3_b & $\begin{array}{l}\text { Creditors' rights protection has a negative direct effect } \\
\text { on leverage }\end{array}$ & 14 & $\begin{array}{l}\text { rights protection (creditors or shareholders) jointly } \\
\text { mediate the effect of the development of bank sector or } \\
\text { stock market, respectively, on leverage }\end{array}$ \\
\hline D4_a & $\begin{array}{l}\text { Shareholders' rights protection has a negative direct } \\
\text { effect on leverage }\end{array}$ & I5 & $\begin{array}{l}\text { Corruption lessens the direct effect of shareholders' rights } \\
\text { protection on leverage }\end{array}$ \\
\hline$D 4 \_b$ & $\begin{array}{l}\text { Shareholders' rights protection has a positive direct } \\
\text { effect on leverage }\end{array}$ & I6 & $\begin{array}{l}\text { Capital formation, mediated by shareholders' rights } \\
\text { protection, has negative indirect effect on leverage }\end{array}$ \\
\hline D5 & $\begin{array}{l}\text { Judicial system quality has a positive direct effect on } \\
\text { leverage }\end{array}$ & & $\begin{array}{l}\text { Economic growth, mediated by industry munificence, } \\
\text { has a negative indirect effect on leverage }\end{array}$ \\
\hline D6 & Corruption has a positive direct effect on leverage & & \\
\hline D7_a & Inflation has a positive direct effect on leverage & & \\
\hline$D 7 \_b$ & Inflation has a negative direct effect on leverage & & \\
\hline D8 & Economic growth has a positive direct effect on leverage & & \\
\hline D9_a & Capital formation has a positive direct effect on leverage & & \\
\hline$D 9 \_b$ & Capital formation has a negative direct effect on leverage & & \\
\hline
\end{tabular}

C-Hypothesis 13: The quality of the judicial system enforces the effect of shareholders' rights protection on leverage, irrespective of the sign of the relationship. 
Moreover, we can expect a joint effect of these two mediating effects (JUDIC, on the one hand, and CREDRIGHTS and SHARIGHTS, on the other hand) on bank sector and stock market development, respectively. We formulate the following hypothesis, which holds in every scenario, irrespective of the sign of the relationship between investor rights protection and leverage, based on the assumed perspective:

C-Hypothesis I4: Both the quality of the judicial system and the investors' rights protection (creditors' or shareholders') jointly mediate the effect of the development of bank sector or stock market, respectively, on leverage.

Similar considerations can be made about the corruption level of a country. Corruption increases the investors' risk: however, since debt obligations are legally binding, it is easier to expropriate equity holders than debt holders, and therefore we expect that the corruption level positively affects leverage and lessens the shareholders' rights protection, increasing its negative influence on leverage or, alternatively, reducing its positive influence.

\section{C-Hypothesis D6: Corruption has a positive direct effect on leverage.}

C-Hypothesis I5: Corruption lessens the direct effect of shareholders' rights protection on leverage, enhan cing its negative impact or, alternatively, reducing its positive impact.

The protection of creditors' rights is likely to moderate the impact on leverage of some firm-specific determinants. Referring to the above discussion about the rationales of firm-specific determinants of leverage (see section 3.2.2), we assume that a higher creditors' rights protection moderates the negative impact of operating risk and the positive effect of asset tangibility on financial leverage, reducing both. Therefore, when laws and their enforcement give a better protection to lenders, the bank system is likely to offer more credit to firms with poor collateral and volatile returns.

F-Hypothesis I2: The operating risk, mediated by creditors' rights protection, has a positive indirect effect on leverage, that partially compensates its negative direct impact.

F-Hypothesis I3: The asset tangibility, mediated by creditors' rights protection, has a negative indirect effect on leverage, that partially compensates its positive direct impact.

Lastly, we hypothesize the effects of the macro-economic characteristics on leverage, according to the international theoretical and empirical background outlined above (see section 3.2.3), and consider their mediated effects, briefly discussed as follows.

When we consider the positive effect of capital formation on leverage, since it is assumed to proxy the firm's financial needs, we can assume that this effect could be mediated by the degree of shareholders' protection, expecting an indirect mediated effect on leverage, since a higher shareholders' protection favours the choice of equity vs. debt.

C-Hypothesis I6: The capital formation, mediated by shareholders'rights protection, has a negative indirect effect on leverage, that reduces its positive direct effect.

The industry munificence can explain the firm's ability to convert the economic growth of a country into economic returns and therefore retained earnings. To control for this effect, we can hypothesize a mediating effect of industry munificence (i.e. the \%EBIT variable) on the positive impact of economic growth on leverage: firms operating in growing and munificent economies need less external funds (i.e. debt) for financing their investments, since they rely on higher retained earnings.

C-Hypothesis I7: Economic growth, mediated by industry munificence, has a negative indirect effect on leverage, that decreases its positive direct effect.

\subsubsection{Methodology and Model Structure}

There are many econometric models proposed in the academic literature that investigate which country determinants have an impact on the firms' financial structure. These models present several common features, since they are almost exclusively based on the use of panel data models, both with fixed and random effects (Aggarwal-Kyaw, 2009; Alves-Ferreira, 2011; Giannetti, 2003; Fan et al., 2012).

In general, the financial structure of a company is affected by both its typical profile (firm specific) and that of its business (industry specific), as well as by the geographic region in which it operates (country specific).

The way in which these variables show their impact on the firm's financial structure can take different forms: we can have a so-called "direct" effect, explained by a relationship of dependency between two variables, and a so-called "indirect" effect, described by a relationship of dependency among three or more variables. For example, if $\mathrm{Y}$ is the response variable, and $\mathrm{X} 1$ and $\mathrm{X} 2$ are two variables that affect $\mathrm{Y}$, we can reasonably assume 
that $\mathrm{X} 1$, in addition to its impact on $\mathrm{Y}$, could also affect $\mathrm{X} 2$ and, hence, again $\mathrm{Y}$. In the first case, we say that the impact of $\mathrm{X} 1$ on $\mathrm{Y}$ is "direct", while in the second case it is "indirect".

The use of models based on panel data does not allow the explicit identification of possible indirect effects among the analysed variables, so that in many studies (Hall et al., 2004; Fan et al., 2012; Aggarwal-Kyaw, 2009) the indirect effect is not considered at all. Furthermore, these models force an a-priori choice between estimators with fixed versus random effects, exclusively based on the outcome of a test of hypotheses.

Other methods suggested in the literature imply the estimate of the different effects (direct and indirect) with distinct models (de Jong et al., 2008; Giannetti, 2003), or with the inclusion of interaction variables, i.e. variables obtained as a product of the variables assumed to be triggers of indirect effects (Alves-Ferreira, 2011; Antoniou et al., 2008).

In the first case, we first estimate the direct effects, ignoring the others; however, if the latter are significant, their omission causes an incorrect specification of the model, producing biased estimates (Green, 2002). When we use the direct effects estimated with a first model, for estimating the indirect effects with a second model, the bias has an impact also on the estimates obtained in that second phase.

Furthermore, if we estimate the country effect by using separate equations for each country or including country dummy variables in the same equation, we ignore the possible interaction among countries: a comparison among them is only feasible in terms of comparison of coefficients, separately estimated for each country.

In this paper we suggest a model based on a unique sample - in which countries are not identified through the inclusion of dummies - and the country effect is measured estimating the coefficients of both the country variables observed in the various countries (direct effects) and the firm and industry variables, whose effect is mediated by the same country variables (indirect effects).

In this way, the intrinsic characteristics of a single country are explicitly included in the model, so that it is possible to estimate a coefficient for each of them, considering the variability of some characteristics among countries.

As far as the second type of methodology is concerned, using the product among variables as a proxy of the indirect effects, does not allow the identification of a possible endogeneity relationship among exogenous variables (Kline, 2011; Kaplan, 2004). In fact, if we include in the model as a regressor the variable $\mathrm{X} 1 * \mathrm{X} 2$ for identifying the possible impact of $\mathrm{X} 1$ on $\mathrm{Y}$ through $\mathrm{X} 2$, we ignore the fact that the same $\mathrm{X} 2$ could be dependent on X1.

In other terms, this is like ignoring possible causality relationships among regressors, that, as generally known (Hayashi, 2000), produces inconsistent estimates of the model's parameters.

Another category of models is that of the hierarchical linear models (HLM), used for example by Kayo-Kimura (2011), whose choice is certainly appropriate, since it allows to consider the multilevel nature of the determinants. In fact, these methodologies consider the ways in which the variables interact to produce the distribution of the observed frequencies; at the same time, allow the identification of possible indirect effects of the determinants, through the estimate of the so-called random coefficient models. In relation to this type of models, we should point out that the definition of levels, i.e. the criteria underlying the classification of the observations, is extremely important. For example, the use of time as a first aggregation level of the observed data (like in Kayo-Kimura, 2011) could lead to the consideration of cross-sectional subsets of observations, and therefore to the loss of the information related to the time variability of all the determinants involved in the model estimation in the subsequent aggregation levels.

Our methodology is based on simultaneous equation systems (Greene, 2002), that allow the evaluation, within a single model, of the overall set of relationships among all the variables, through the estimate of the variance and co-variance matrix of the entire system of equations.

Hence, the use of this methodology allows the control of both the direct and indirect effects (effect decomposition: Kline, 2011), as well as of the possible endogeneity relationships among regressors, leading to consistent estimates of the parameters. The estimated system can be classified as a so-called Mediational Model (Mathieu-Taylor, 2006), and is based on the analysis of causal sequences starting from the theoretical assumptions about the cause-effect relationships among the variables. This class of models allows the evaluation of the existence, intensity, and direction of the effects. As far as the time variability of the determinants is concerned, we avoided a time (year)-based aggregation of the observations to catch the effect of the time variability for all the three classes of determinants specified in the model. 
Our model implies the estimate of the parameters of 8 linear equations. The first one (1) is the equation of interest and explains the effects of the determinants on leverage (LEV), while equations (2) - (8) are estimated only to make explicit their mediating role in the model: they cannot be considered as explanatory of the left-hand side variable, i.e. the coefficients estimated in each of these equations are only used to obtain the indirect effects in equation (1).

In other words, the parameters of the equations from (2) to (8) should be interpreted from a path analysis perspective (Kline, 2011), in the sense that they are instrumental for showing the indirect effects on leverage of some of the variables considered. If, for example, we are interested in assessing the TANG's effect on LEV, we need to assess both its direct effect - measured through the estimate of $\beta_{21}$ in equation (1) - and its indirect effect, mediated by CREDRIGHTS, in equation (7). In the second case, the effect will be measured multiplying the coefficients $\beta_{27}$ and $\gamma_{31}$.

The estimate of different equations for catching the indirect effects on LEV allows the identification of paths, i.e. the identification of the indirect effects that go through two or more mediating variables. For example, as far as the TANG's effect on LEV is concerned, in addition to the effect mediated by CREDRIGHTS, it is also necessary to consider what is being mediated by JUDIC. In this case, the effect of TANG on LEV will be obtained multiplying the coefficients $\beta_{27}, v_{65}$ and $\gamma_{51}$.

Hence, the overall indirect effect of TANG on LEV could be expressed as follows (see Figure 1): $\left(\beta_{27} * \gamma_{31}\right)+\left(\beta_{27} * v_{65} * \gamma_{51}\right)$

The following is the final structure of the model:

$$
\begin{aligned}
& L E V_{t i j h}=\alpha_{1}+\gamma_{11} R O A_{t i j h}+\beta_{11} N D T S_{t i j h}+\beta_{21} T A N G_{t i j h}+\beta_{31} L I Q 1_{t i j h}+\beta_{41} L I Q 2_{t i j h}+\beta_{51} \text { OPRISK }_{t i j h}+ \\
& +\psi_{11} \text { BUSRISK }_{t 0 j h}+\psi_{21} \mathrm{HH}_{t 0 j \mathrm{~h}}+ \\
& +\gamma_{21} \text { BANKPRIVCR_1 }{ }_{t 00 \mathrm{~h}}+v_{11} \text { INFL } \mathrm{t}_{t 00 \mathrm{~h}}+v_{21} \text { CAPFORM } 1_{t 00 \mathrm{~h}}+v_{31} L N_{-} \text {DLC } C_{t 00 \mathrm{~h}}+v_{41} \text { STOCKTURN } \mathrm{t}_{t 00 \mathrm{~h}}+ \\
& +\gamma_{31} \text { CREDRIGHTS }_{000 \mathrm{~h}}+\gamma_{41} \text { CORR }_{000 \mathrm{~h}}+\gamma_{51} \text { JUDIC }_{000 \mathrm{~h}}+ \\
& +d_{11} @ 1_{0000}+d_{21} \text { MANUFACT } T_{0000}+\varepsilon 1_{t i j h} \\
& R O A_{t i j h}=\alpha_{2}+\psi_{32} \% E B I T_{t 0 j h}+\beta_{12} \operatorname{NDTS}_{t i j h}+ \\
& +\varepsilon 2_{t i j h} \\
& \text { BANKPRIVCR }_{t 00 h}=\alpha_{3}+\psi_{13} \text { BUSRISK K }_{t 0_{j h}}+\psi_{23} \mathrm{HH}_{t 0 j h}+ \\
& +\varepsilon 3_{t i j h} \\
& \% E B I T_{t 0 j h}=\alpha_{4}+v_{54} V A R_{-} G D P_{-} 2_{t 00 h}+ \\
& +\varepsilon 4_{t i j h} \\
& J_{U D I C} 000 h=\alpha_{5}+v_{65} C_{R E D R I G H T S_{000 h}}+v_{75} \text { SHARIGHTS }_{000 h}+v_{35} L N_{-} \text {DLC }_{t 00 h}+ \\
& +\varepsilon 5_{t i j h} \\
& \text { CORR }_{000 h}=\alpha_{6}+v_{76} \text { SHARIGHTS }_{000 h}+ \\
& +\varepsilon 6_{t i j h} \\
& \text { CREDRIGHTS }_{000 h}=\alpha_{7}+\beta_{27} \text { TANG }_{t i j h}+\beta_{57} \text { OPRISK }_{t i j h}+ \\
& +\varepsilon 7_{t i j h} \\
& +\varepsilon 8_{t i j h}
\end{aligned}
$$

where $t$ is the time index, $i$ the dimensional class, $j$ the industry sector, and $h$ the country; the indices' coefficients identify, in order, the regressor and the equation in which it appears. 
The final structure of the tested model, described above, is the result of a broad testing process of all the hypotheses listed in section 3.3.1, together with the selection of the measured proxies for the various types of determinants, using, as a criterion, the significance of both the proxies and the hypothesized links.

We selected the variables included in each equation thanks to the identification of all the significant paths among them, making sure that every single indirect effect of these variables on LEV would be considered. We firstly investigated the links related to the firm specific variables, and subsequently we formulated further hypotheses on the country and industry determinants' effects.

For each category of explanatory variables, we verified the nature of their possible effect on LEV. We can distinguish four different types of "mediation" of the effect:

- in a first case, the nature of the effect is direct, i.e. it is not mediated by other variables (direct effect)

- in a second case the effect is only indirect (indirect effect), i.e. there is just an effect mediated by one or more variables, but without any direct effect

- in a third case we have a partial mediation, in the sense that we have both a direct and an indirect effect

- finally, we have a full mediation when the exhaustive specification of all the indirect effects makes the previously identified direct effect insignificant.

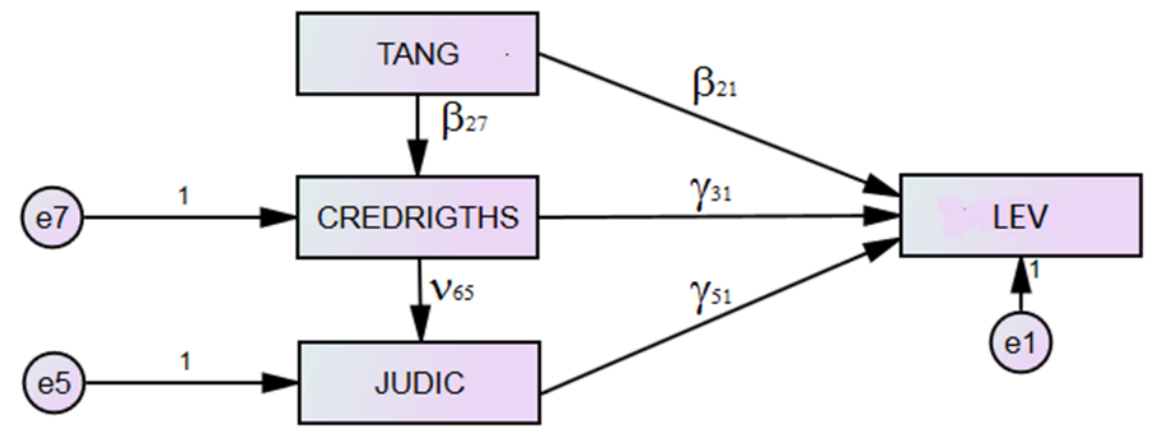

Figure 1. Example of direct and indirect paths

As said above, the 4 types of effects cannot be seen with the simple inclusion of "interactions" among variables in the model, since they prevent from identifying the directions of the causal relationships among the variables.

The mediational models, thanks to their ability to assign a direction to the identified relationships, are therefore the most appropriate tool for hypothesis testing.

The estimate of the unknown parameters of the system of equations was obtained with the "maximum likelihood with complete information" method: the estimates therefore are consistent, efficient, and sufficient.

To assess the model's fitting to the observed data, we used the usual and most popular indicators in the literature, with reference to the SEM models:

1. Akaike Information Criterion (AIC), a test of relative model fit. The preferred model is that with the lowest AIC value. $A I C=2 k-2 \ln a$ ? $(L)$, where $k$ is the number of parameters in the statistical model, and $\mathrm{L}$ is the maximized value of the likelihood of the model;

2. Root Mean Square Error of Approximation (RMSEA). RMSEA values smaller than 0.1 indicate a good fit. A RMSEA value of 0.1 or larger indicates a poor fit.

3. Comparative Fit Index (CFI). In examining baseline comparisons, the CFI largely depends on the average size of the correlations in the data. If the average correlation between variables is relatively low, the CFI will decrease as well. A CFI value of 0.90 or higher is desirable.

\section{Results}

\subsection{The Path Model Graph}

In this section we illustrate the main results of the analysis. As already said (see section 3.3), we use a simultaneous estimation approach, path analysis, to measure firm, industry, and country effects on capital structure. Path analysis involves the analysis of sets of relationships among variables, so that independent variables in one equation become a dependent variable in another equation (Smith-Smith, 2004). 
Figure 2 shows the path structure of the tested model.

In the complete model the correlations between variables were also estimated, but since we are interested on their causal relationships, and to facilitate the interpretation of the graphic model, all the correlations between variables (two-headed arrows) are not displayed, and only causal effects between variables are represented (one-headed arrows). The rectangle in Figure 2 represents the observed variables, while the circles represent the residuals of each equation. All mediation variables become dependent variables when used as mediation terms between two variables. In other words, if one-headed arrow is pointing towards a variable, the latter becomes a new dependent variable, which has as many independent variables as the arrows pointing towards it. For example, SHARIGHTS is a dependent variable influenced by CAPFORM_1 and STOCKTURN_1, and in the meantime it influences CORR (see equations 6 and 8 in $\S 3.3 .2$ ). It is easy to see that the structure is quite complex with several flows of information following different paths, but all converging to financial leverage.

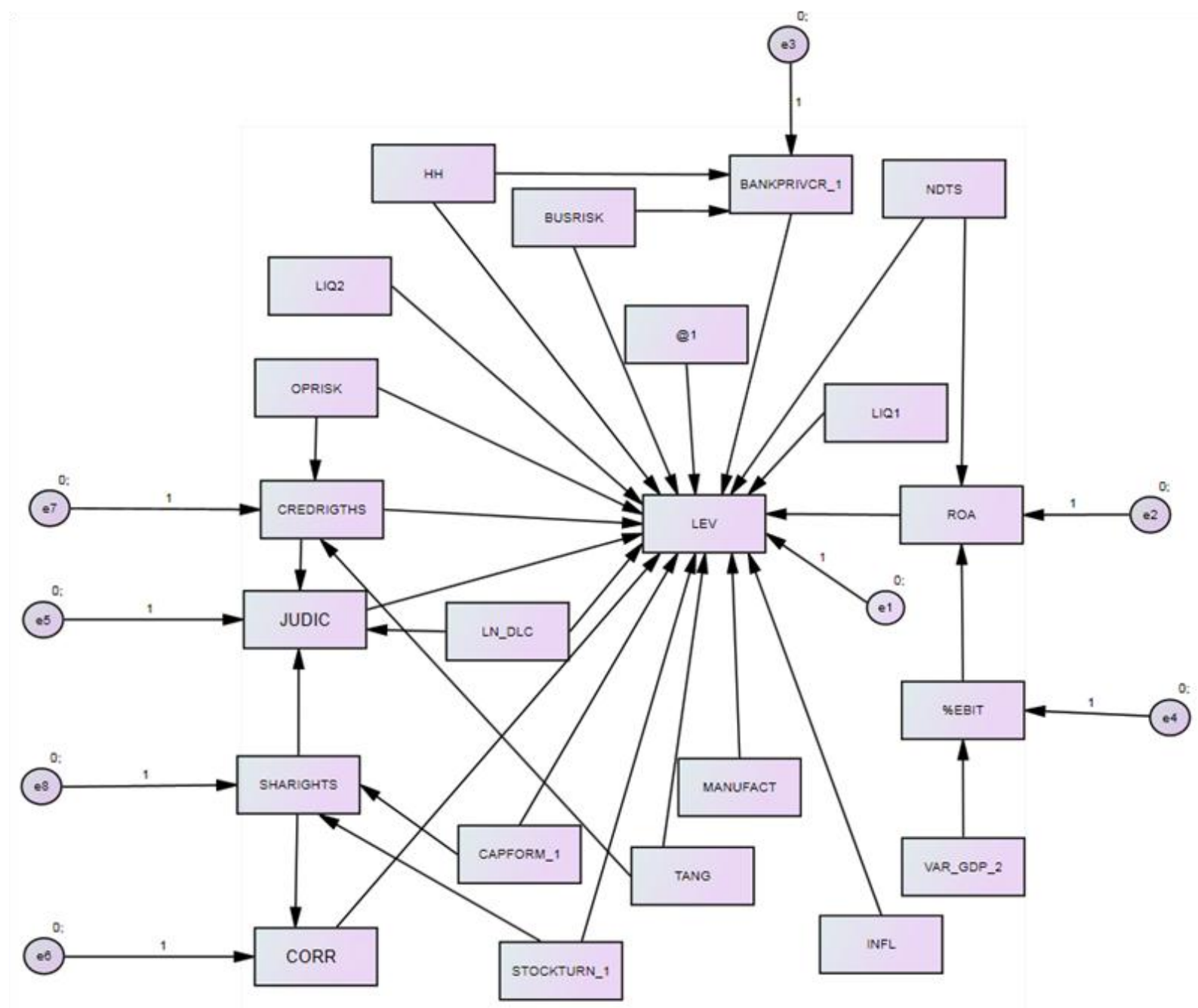

Figure 2. Path model graph

Table 4 presents the results of the model estimation, and Table 5 the information criteria used to evaluate the model fit ${ }^{3}$. These tests are usually difficult to interpret in terms of quality of the model (poor or good fit), since they take absolute values; to overcome this difficulty, we compare the absolute values obtained from the estimation of the model with the test values corresponding to both the empty and the saturated model. The test value from an empty model (i.e. the model which only includes the intercept) are often used as a lower threshold, because this model does not give any information about the relationships among variables; on the contrary, the saturated model explores all the possible relationships among variables (it includes both correlations and causal

3 For brevity, descriptive statistics of the independent variables are omitted. However, dataset is publicly available: BACH-ESD dataset is free as well as economic data from IMF/World Bank and institutional characteristics of countries (Spamann, 2010); in addition, the relevant level of data disaggregation is the same as in BACH-ESD dataset. 
relationships). Table 5 shows that the three fit tests are closer to those of the saturated model compared to those of the empty model. As we said above (section 3.3.2), some thresholds for the CIF and RMSEA tests are widely used. Therefore, we can conclude that the estimated model provides a good representation of the linkages among the considered variables.

\subsection{Industry and Size/Firm Effects}

As far as the firm and industry direct effects on leverage are concerned, the results achieved in this study are consistent with those of the mainstream literature.

Panel A of Table 4 shows a negative effect between leverage and profitability (ROA) (Giannetti, 2003; de Jong et al., 2008; Alves-Ferreira, 2011). This finding is consistent with the $\mathrm{POH}$ and asymmetry information theory (F-Hypothesis D1_b). Due to the information asymmetry between investor and management, external funds are more expensive than retained earnings; more profitable firms have less debt in their capital structure because they prefer to finance their new investments with internal funds, that are cheaper than the external ones.

The ratio of current assets to total assets (LIQ1) has a positive effect on leverage: we assume that this ratio measures the proportion of working capital on the investment structure of the firm. Firms with larger current assets increase their short-term liabilities, that better match the investment maturity. On the other hand, liquidity measured as a ratio of cash and cash equivalents to total assets (LIQ2) negatively affects leverage, confirming what we found on the impact of ROA: firms with more funds available need less debt to finance their investments. These results are consistent with our hypotheses (F-Hypotheses D6 and D7).

Conversely, tangibility (TANG) has a positive correlation with leverage, as hypothesized (F-Hypothesis D3). This is a widely shared result in the classical literature (Stultz-Johnson, 1985; Giannetti, 2003; de Jong et al., 2008; Aggarwal-Kyaw, 2009, Fan et al., 2012). In case of bankruptcy, tangible assets are more likely to maintain their market value than the intangible ones. Therefore, the risk of lending to firms with higher tangible assets is lower and, hence, lenders will demand a lower risk premium. Furthermore, a firm's opportunity to engage in asset substitution can be reduced by secured debt, which reduces the agency costs and hence the cost of borrowing. Asset tangibility improves the chances to obtain loans because lenders have a better opportunity to recover them in case of default (Jensen-Meckling, 1976).

The present value of bankruptcy costs also depends on the firm's operational risk (OPRISK), that proxies the returns' volatility and increases the probability of incurring in bankruptcy. For this reason, a negative effect on leverage is generally expected (F-Hypothesis D4), but we found instead a positive one. We can explain this evidence observing the financial-system orientation of our sample. The negative impact of operational risk on leverage especially holds for firms operating in market-based countries, characterized by more distance between lenders and borrowers. In bank-oriented countries, firms have closer ties with lenders, that reduce the actual cost of failure to service debt (Antoniou et al., 2008). Furthermore, when we consider closely held firms, we can expect that their risk aversion is higher, and therefore using more debt in their financial structure allows them to share the business risk with lenders.

The non-debt tax shield (NDTS) reduces earnings before interest and taxes, lowering the net advantage of the tax shield. Our results show a negative coefficient for this variable, consistent with our hypotheses (F-Hypothesis D2). Firms with higher depreciation rates do not need high debt levels to shield their earnings, and therefore tend to have less debt (hence the substitution effect prevails).

The effect of the firm's size is studied using a dummy variable, that splits the sample into two groups: small size firms and medium-large firms (@1). The positive coefficient evidences that small size firms are more leveraged than medium and large ones. This means that the correlation between leverage and size is negative (Rajan-Zingales, 1995). More asymmetric information and smaller and volatile retained earnings in small firms tend to push their financial choices towards debt rather than equity. Furthermore, small firms are often more closely held or family owned and therefore more concerned about losing control (F-Hypothesis D8_b).

In testing the model, we introduced the industry-relative firm's characteristics, but we did not find any of them statistically significant. Simultaneously including firm and industry determinants in the explanatory model is likely to absorb both the absolute and the industry-relative effect of the firm's characteristics. 
Table 4. SEM estimation: the direct and indirect effects on leverage

The first column shows all the significant explanatory variables, split into firm, industry and country effects. There are reported both the direct (column 2 ) and indirect (column 3 ) effects. The multi-path indirect effects are decomposed (greek letters) and the corresponding coefficients of the equation model (\$ 3.3.2) are reported. Column 4 indicates the mediation variables. Column 5 shows the total effect on leverage, obtained as sum of direct and indirect effects.

Robust standard errors are given in parentheses. $* * * * * * *$ indicate that coefficients are significant at the $10 \%, 5 \%$ and $1 \%$ levels, respectively.

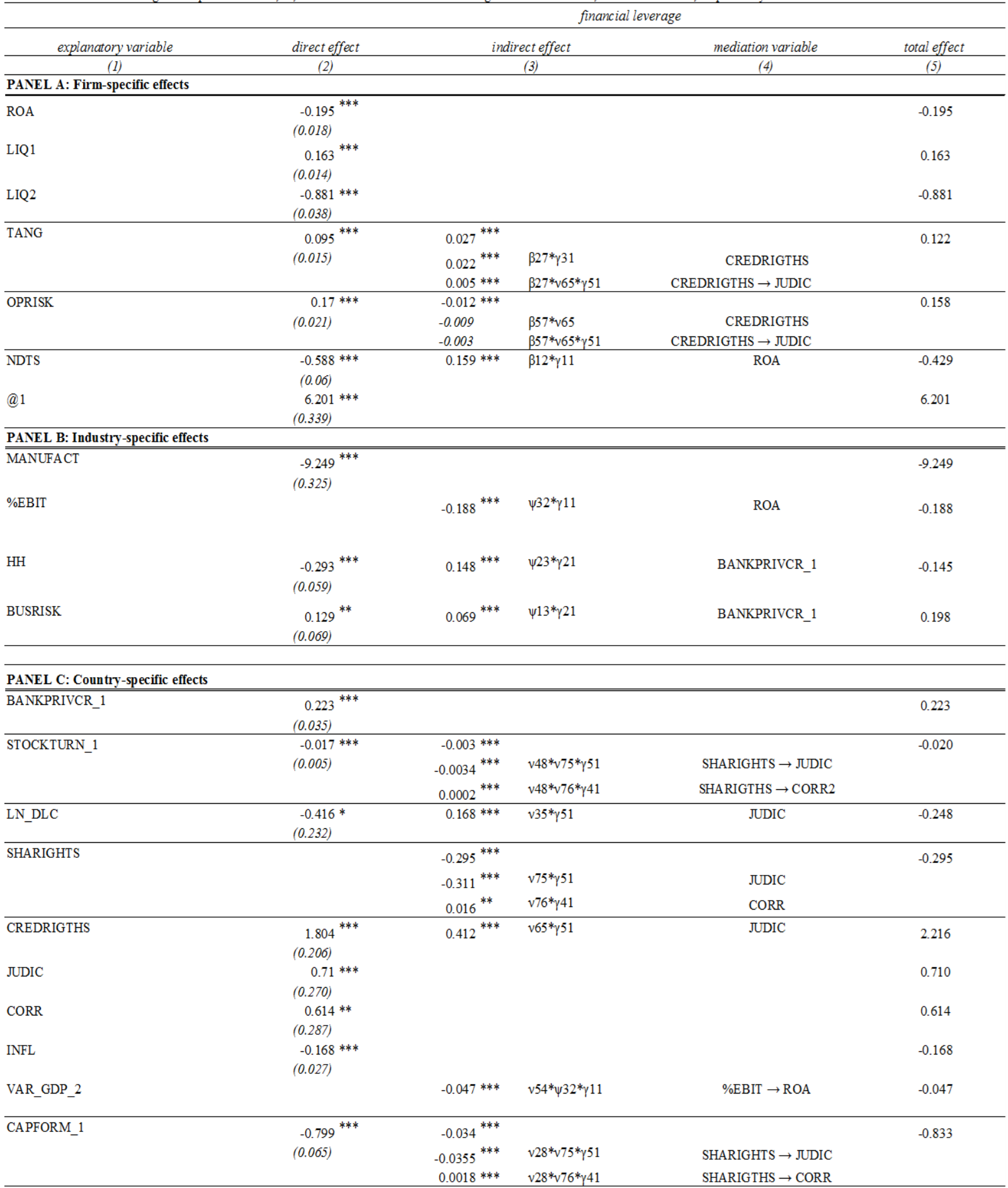

Table 5. The goodness of model fit

\begin{tabular}{lrrrr}
\hline \multicolumn{1}{c}{ MODEL } & \multicolumn{1}{c}{ AIC } & \multicolumn{1}{c}{ BCC } & \multicolumn{1}{c}{ RMSEA } \\
\hline tested model & 5603.865 & 5605.286 & 0.907 & 0.092 \\
saturated model & 550 & 552.752 & 1 & $/$ \\
empty model & 56366.969 & 56367.41 & 0 & 0.229 \\
\hline
\end{tabular}


Panel B of Table 4 shows the results of the industry determinants on leverage. As already said, we used many proxies of the same determinant: since they are mutually correlated, just the proxy that better explains each determinant was selected by the model. In addition, the time-variant industry variables replace in this model the industry dummy variables, mainly used in the international literature.

The first variable is the business risk (BUSRISK), that proxies the dynamism of an industry: we found a positive linkage of this variable with leverage, that contradicts the expected sign (S-Hypothesis D2). However, since BUSRISK measures the industry cross-sectional (i.e. among firms) dispersion of ROS, its positive impact on leverage could confirm the better ability of the bank system in selecting borrowers, compared to the equity market. From a different point of view, the perception of higher risk in dynamic sectors could make equity more expensive and orient firms towards debt.

Munificence proxies do not have a statistically significant direct effect on leverage, but an indirect one, which will be discussed at the end of this section.

The Herfindahl-Hirschman (HH) index has a negative impact on leverage. The negative effect is consistent with the previously found evidence that small and risky firms tend to be more leveraged, since a competitive industry includes riskier and smaller firms than a concentrated one (S-Hypothesis D3_b).

The coefficient of the manufacturing dummy (MANUFACT) is negative and statistically significant: it implies that firms in tertiary industries (in our sample, trade and services) are more leveraged than manufacturing firms (S-Hypothesis D4).

Two indirect effects were found, concerning firm and industry determinants. Firstly, non-debt tax shield (NDTS), when mediated by profitability (ROA), shows a positive coefficient, confirming the existence of an income effect of NDTS (Dammon-Senbet, 1988) (F-Hypothesis I1). Higher depreciations derive from larger capital expenses (new investments), that generate higher profits. If a firm is profitable, the firm's actual tax charge increases, since it has higher taxable income. However, the substitution effect still prevails, since the total effect of NDTS on leverage is negative, but smaller than the stand-alone direct effect.

Secondly, the industry's munificence (\%EBIT) is fully-mediated by the firm's profitability (ROA) and negatively influences leverage: this means that, thanks to the industry's munificence, profitable firms can rely on larger retained earnings and therefore tend to have less debt (S-Hypothesis I1). The mediated effect obscures the direct effect of industry's munificence on leverage.

Some indirect effects of firm and industry determinants are also found, mediated by country characteristics. We prefer to discuss them in the next section, after the direct country effects.

\subsection{Direct and Indirect Country Effects}

We discuss here the effects of country determinants on leverage, both as direct determinants of leverage and as mediating variables of other determinants.

Many models were tested. This step by step process provided two useful results. First, the adopted methodology highlighted the existence of indirect effects and the type of mediation (full or partial). Second, creating multiple intermediate models permitted to select the best one in terms of goodness of fit, i.e. the final model described in Figure 2. The selection process stopped when the model fit was hardly improvable. Panel C of Table 4 shows the statistically significant coefficients for country variables, even after controlling for a broad range of industry and firm determinants, already discussed above.

The degree of stock market development should reduce the cost of equity and the asymmetry of information, pushing firm to rely more on equity, and lowering their leverage. Both liquidity (STOCKTURN_1) and size (LN_DLC) of the stock market show negative statistically significant coefficients, that confirm the hypothesis (C-Hypothesis D1).

Furthermore, the impact of these country variables is mediated by the institutional protection given to the shareholders. The impact on leverage of the mediation between financial and institutional characteristics is statistically significant. The liquidity of the stock market goes through two double mediation paths: firstly, through shareholder rights protection (SHARIGHTS) and judicial effectiveness (JUDIC); secondly, through shareholder rights protection (SHARIGHTS) and corruption (CORR). The two indirect effects have a negative and positive influence on leverage, respectively, but the negative effect still prevails, amplifying the direct effect of STOCKTURN_1 (C-Hypothesis I3). The first combined mediation tries to catch the "actual" shareholder rights protection, which represents the combined effect generated by the shareholder right protection (stated by law) and the efficiency and efficacy of the institutional system, called to enforce this right protection. The second 
one is the result of the lessening effect of corruption on leverage, even accounting for a better shareholder rights protection, supporting our C-Hypothesis 15.

The indirect effect of the stock market size (LN_DLC) on leverage, when mediated by the judicial quality, is positive (according to C-Hypothesis II), lowering the negative total effect. This means that in countries with many listed firms and an effective judicial framework, lenders benefit from a better firms' transparency and hence firms use more debt for financing.

The effect of bank sector development (BANKPRIVCR_1) is positive, consistent with the international evidence (de Jong et al., 2008; Kayo-Kimura, 2011) and our C-Hypothesis D2. Furthermore, the bank sector development mediates two industry determinants, generating two indirect effects. The first mediation is between industry dynamism (BUSRISK) and le verage: the indirect effect is positive, which means that a more developed bank sector is more efficient in evaluating and monitoring the borrower's risk and therefore can increase its credit lines; S-Hypothesis I2 is confirmed: since the direct effect of BUSRISK on leverage is positive, the mediation effect enhances the overall positive effect. The second mediation effect is between industry concentration (HH) and le verage: the coefficient is positive, contrasting our hypothesis (C-Hypothesis 13 ). It should be noted that the total effect of concentration on leverage is negative, i.e. firms in concentrated industries are less leveraged than firms in competitive industries. What we observe is that firms in concentrated industries are more leveraged in countries where the bank sector is more developed than in countries where the bank sector is less developed: this evidence is consistent with the assumption that a more developed bank sector increases the chances of having access to bank credit. It is more difficult to explain the following emerging evidence: firms in competitive industries are less leveraged in countries where the bank sector is more developed than in countries where it is less developed; if we consider the positive impact of risk on financial leverage, found in this study, both at firm and industry level, we can explain this evidence in terms of signalling content of bank debt for risky firms. In countries where the bank sector is more developed, having access to bank credit is more widespread and therefore weakens as a guarantee of reputation for risky firms, i.e. firms operating in more competitive industries.

The degree of creditor protection has a positive correlation with leverage, supporting the supply-side perspective (C-Hypothesis D3_a). Countries with higher creditor rights protection (CREDRIGHTS) have more leveraged firms. In addition, the effect of the "actual" creditor rights protection is positive, too: the quality of the judicial system (JUDIC) enhances the positive effect of the creditor protection, pushing lenders to give more credit thanks to the availability of better protection (C-Hypothesis I2). The direct effect of shareholder protection (SHARIGHTS) on leverage is negative and significant (C-Hypothesis D4_a), but turned statistically insignificant when mediated by judicial system and level of corruption: this shows a full-mediation effect of these variables on leverage. As we see in Figure 2, the final model does not show a direct effect of shareholder rights protection on leverage, but only a negative indirect one (which confirms the C-Hypothesis I3): this means that the protection actually (rather than nominally) granted is the factor that better encourages firms to use equity for financing their needs. The indirect effect mediated by the level of corruption (CORR) is positive, confirming the C-Hypothesis 15 . Higher levels of corruption tend to reduce the benefit of shareholder rights protection when using equity, switching the preference to financial debt. However, the overall indirect effect remains negative.

The "actual" creditor rights protection, i.e. the indirect effect of CREDRIGHTS mediated by JUDIC, also influences two firm's determinants. As shown in Figure 2, this variable mediates the effects of asset tangibility (TANG) and operational risk (OPRISK), on the one hand, and financial leverage, on the other.

The hypotheses (F-Hypotheses I2 and I3) formulated for these two indirect effects, assuming a supply-side perspective and the actual protection rather than the nominal one, are both rejected. The presence of a higher protection enhances the effect of providing tangible assets as collateral for increasing bank debt. This means that a demand-side perspective prevails: in countries where the creditor rights are more protected, the cost of debt for the borrowers is higher, due to higher distress and bankruptcy costs (lenders can more efficiently claim the enforcement of their credit contracts); therefore, the borrowers who can offer more tangible assets as collateral are more oriented to use debt, since they reduce these costs.

As far as the operating risk is concerned, we obtain a negative mediating effect of creditor rights protection, that reduces the positive direct effect of firm's risk on leverage. Again, a demand-side perspective prevails: riskier firms tend to share the business risk with banks (the direct effect of OPRISK is positive), for various reasons, discussed above (see section 3.2.2). In countries where creditors are more protected, bankruptcy costs are higher and therefore this risk sharing is less convenient for borrowers. 
Moreover, the direct effects of both the quality of judicial system and the corruption level are positive, as expected (C-Hypotheses D5 and D6). Therefore, these countries' institutional characteristics have an overall positive effect on leverage through both the direct and the mediating effects.

The last part of Table 4 shows the coefficients of the statistically significant macroeconomic determinants. The 2-year average annual economic growth (VAR_GDP_2) is fully mediated, i.e. the direct effect on leverage becomes insignificant when mediated by industry munificence and firm's profitability: the indirect effect is negative, consistent with the POH perspective (C-Hypothesis I7). Inflation (INFL) has a negative direct effect on leverage, that confirms the supply-side viewpoint (C-Hypothesis D7_b). The negative coefficient of lagged capital formation (CAPFORM_1) qualifies it as a proxy of retained earnings; furthermore, this effect is enhanced when mediated by shareholder rights protection, generating a negative indirect effect. Hence, the total effect is boosted in countries where high shareholder rights protection reduces the information asymmetry, lessening the advantage of debt with respect to equity: this evidence supports the $\mathrm{POH}$ perspective, and our country hypotheses $D 9 \_b$ is confirmed.

Finally, the year dummies did not show any statistically significant relationship with leverage: it is likely that macroeconomic and financial time-variant country's characteristics better catch the time fixed effects.

\section{Robustness Tests}

We check the robustness of our explanatory model on country effect, testing it with different sub-samples, split based on size and time. In particular, we split the entire sample into two sub-samples based on size: a sub-sample of small firms (1.540 observations) and a sample of medium and large firms (3.080 observations); furthermore, we split the entire sample into two sub-samples based on time, in order to separate two different economic phases occurred during the period considered in the entire sample: a sub-sample refers to the small crisis period (2000-2004, with 2.310 observations), while the other sub-sample refers to the subsequent expansion period (2005-2007, with 1.386 observations). We decided to omit the last abnormal two years (2008-2009), characterized by the recent crisis. The objective is to test the general robustness of the explanatory model with different firms' sizes and economic phases. We verify the robustness of the model, comparing the signs and statistical significance of the determinants' effects on financial leverage of each sub-sample to those previously found in the entire sample.

We omit the detailed results for brevity. Summarizing, we obtained that:

a) most coefficients are statistically significant and their signs and values are similar to those of the entire sample; however, some differences emerge and can be explained, observing the different nature of the sub-samples;

b) we observe for the small firms, due to their wider information asymmetries, the following differences:

- the stock market represents a viable alternative for financing investments only in countries where the stock exchange is large (and therefore includes also the small companies)

- the liquidity of the stock market, instead, is not relevant for them

- the information asymmetry enhances the importance of collateral for small firms (TANG): small firms with tangible assets can use more debt because the marginal reduction of the asymmetry is greater for them compared to larger firms, where the coefficient is less significant and negative

- for the same reason, small firms in dynamic sectors (BUSRISK) could represent an exploitable opportunity for banks, that rely on a better selection and monitoring process of the small firm's performance compared to the stock market. Larger firms can rely on a better reputation and they may not need banks to soften their information asymmetry: this explains why the coefficient is not statistically significant for them

- a larger coefficient of the ratio of current assets to total assets (LIQ1) is found on the small firms' sample, which shows the importance of this determinant. Small firms are likely to be characterized by a larger proportion of current assets, since they operate more often in light industries that are less capital intensive and less sensitive to scale economies. Therefore, the relevance of current assets drives their financial needs, that are often financed by short term loans, to match the maturity structure. In the medium-large firms' sample the effect of this determinant is much lower.

- the lagged capital formation's coefficient is smaller for the small firms than for the larger ones (CAPFORM_1). Capital formation may have a lower impact on small firms because their ability to generate and maintain a stable retained earnings level is lower than in larger firms. Therefore, their 
potential retained earnings are a weaker substitute for financial debt. This result is also confirmed by the smaller negative coefficient of profitability (ROA) for small firms.

- as far as the sub-samples based on time periods, we found that the coefficient estimates seem to be robust for different economics phases. All the coefficients in both sub-samples are statistically significant (except for STOCKTURN_1 in the small crisis sample), with the same signs and similar values of the effects of determinants found in the entire sample. This can demonstrate that the significant economic effects are mostly captured by the time-variant country-specific determinants. The indirect country effects are consistent with entire sample, too.

\section{Some Conclusions}

This paper examines how country characteristics affect capital structure decisions in seven European countries, when size-class and industry specific characteristics are also considered in the explanatory model.

The most important empirical findings emerging from the analysis are summarized as follows:

- the country's characteristics have an important impact on firm's leverage, both directly and indirectly;

- among the country's determinants, those regarding the institutional framework are very influential. We note that it is the actual investor protection that influences the capital structure choice, rather than the theoretical one, i.e. that ideally guaranteed by laws. In fact, the quality of the judicial system assures the effectiveness of the investor's protection, allowing for an effective and more rapid enforcement of contracts; the corruption level can vanish this protection, especially of shareholders rights, that are more easily expropriable. We find that the more protected the creditors, the more leveraged the firms; the more protected the shareholders, the less leveraged the firms. Both these findings support the sign expected from the supply-side perspective. However, if we consider the mediating effect of creditor protection on asset tangibility and risk in influencing financial leverage, a demand-side perspective prevails. In fact, in countries where creditors are more protected, the positive effect of asset tangibility on leverage is enhanced: a stronger protection of creditors triggers higher bankruptcy costs, that firms try to contain making use of collateral for guaranteeing their debt; riskier firms in countries where creditors are more protected and bankruptcy costs are higher use less debt to reduce the probability of default;

- the financial system's characteristics of a country also affect the financial leverage. The more developed the bank system, the more leveraged the companies; the more developed the stock market, the less leveraged the firms. It is important to note that the liquidity of the stock market and the size of the stock exchange in terms of number of listed firms are relevant. The latter, however, has a positive indirect effect on lever age, that can be explained in terms of better firms' transparency deriving from being listed;

- as far as the firm- and industry-specific determinants are concerned, our empirical findings importantly support the POH perspective. Firms' profitability and industry's munificence and capital formation increase the retained earnings and therefore lessen the firms' indebtedness. Analogously, both liquid assets availability and economic growth in munificent sectors decrease financial debt. Furthermore, firms are likely to aim at matching the maturity of sources and uses: larger current assets correspond to more debt (probably, short term);

- however, the tax implication of debt is an important determinant at firm level, and we find both the substitution and the income effect of non-debt tax shields;

- we see that small and riskier firms are more leveraged. The positive impact of risk on financial leverage was found at both firm and industry level (the latter measured as a cross-sectional dispersion of ROS among firms). Furthermore, these findings are supported by a negative linkage between industry concentration and financial leverage: more concentrated industries are likely to be characterized by larger firms and more stable competitive pattern among firms. This evidence proves:

- better selecting and monitoring skills of banks with respect to the equity market; the dispersion of profitability among firms and the potential return volatility (the operating leverage is an ex ante measure of operating risk) could represent in this scenario an opportunity rather than a threat for banks; furthermore, the opacity of small and risky firms makes debt less expensive than equity;

- the prevalence of the demand-side perspective: bank debt is likely to be used by risky firms for sharing risk with creditors and signalling business quality and firm reputation; furthermore, the risk aversion of closely held or entrepreneurial firms makes debt more attractive for financing; 
- the macroeconomic characteristics of a country complete the country effect on capital structure choices: inflation reduces the use of debt, as well as the economic growth and the capital formation.

This study presents some limitations. Firstly, it considers a sample of seven European countries and therefore the findings cannot be generalized to different economic, financial, and institutional contexts. Therefore, further research could use an ampler sample, to improve the generalizability of the model. Secondly, the observations are not at firm-year level, but at size-class-industry-year level. As discussed above, this data limitation could overcome some pitfalls of a firm-level analysis, but however it ex ante reduces the variability of the analysed sample and therefore the explanatory power of the model. Further research could eliminate this data aggregation and better exploiting the explanatory model here proposed. In this case, however, a dynamic approach of adjustment to the optimal capital structure is likely to be used, since the observed static leverage measures of individual firms do not approximate their target leverage each year.

The empirical findings here obtained highlight the importance of institutional and financial characteristics of the country where borrowing firms and lending intermediates operate, both directly and mediating the impact of other determinants of capital structure. This means that country characteristics should be considered in managerial decisions as well as in formulating guidelines and rules by regulatory institutions: a one-fits-all approach is not workable. Finally, they show that a demand-side perspective (often omitted in economics and finance) better explains firm behaviours in capital structure choice, especially when firms are small and medium-sized (Watson, 2010).

\section{References}

Acedo-Ramirez, M. A., \& Ruiz-Cabestre, F. J. (2014). Determinants of Capital Structure: United Kingdom Versus Continental European Countries. Journal of International Financial Management \& Accounting, 25(3), 237-270. https://doi.org/10.1111/jifm.12020

Aggarwal, R., \& Kyaw, N. N. A. (2009). International variations in transparency and capital structure: evidence from European firms. Journal of International Financial Management \& Accounting, 20(1), 1-34. https://doi.org/10.1111/j.1467-646X.2009.01025.x

Alves, P. F. P., \& Ferreira, M. A. (2011). Capital structure and law around the world, Journal of Multinational Finance Management, 21, 119-150. https://doi.org/10.1016/j.mulfin.2011.02.001

Antoniou, A., Guney, Y., \& Paudyal, K. (2008). The determinants of capital structure: capital market-oriented versus bank-oriented institutions. Journal of Financial and Quantitative Analysis, 43(1), 59-92. https://doi.org/10.1017/S0022109000002751

Bancel, F., \& Mittoo, U. R. (2004). Cross-country determinants of capital structure choice: A survey of European Firms. Financial Management, winter, 103-132.

Banque de France. BACH-ESD e BACH database, http://www.bachesd.banque-france.fr/?lang=fr

Booth, L., Aivazian, V., Demirguc-Kunt, A., \& Maksimovic, V. (2001). Capital structure in developing countries. Journal of Finance, 56(1), 87-130. https://doi.org/10.1111/0022-1082.00320

Boyd, B. K. (1995). Ceo duality and firm performance. A contingency model. Strategic Management Journal, 16, 301-312. https://doi.org/10.1002/smj.4250160404

Dammon, R. M., \& Senbet, L. W. (1988). The effect of taxes and depreciation on corporate investment and financial leverage. Journal of Finance, 43(2), 357-373. https://doi.org/10.1111/j.1540-6261.1988.tb03944.x

de Jong, A., Kabir, R., \& Nguyen, T. T. (2008). Capital structure around the world: the role of firm- and country-specific determinants. Journal of Banking \& Finance, 32, 1954-1969. https://doi.org/10.1016/j.jbankfin.2007.12.034

Demirguç-Kunt, A., \& Maksimovic, V. (1999). Institutions, Financial Markets, and Firms' Choice of Debt Maturity. Journal of Financial Economics, 54, 295-336. https://doi.org/10.1016/S0304-405X(99)00039-2

Dess, G. G., \& Beard, D. W. (1984). Dimensions of organizational task environments. Administrative Science Quarterly, 29, 52-73. https://doi.org/10.2307/2393080

Djankov, S., McLiesh, C., \& Shleifer, A. (2007). Private credit in 129 countries. Journal of Financial Economics, 84, 299-329. https://doi.org/10.1016/j.jfineco.2006.03.004

Donaldson, G. (1961). Corporate debt capacity. Cambridge: Harvard Press.

Donaldson, G. (1984). Managing corporate wealth. Santa Barbara: Praeger. 
Fan, J. P. H., Titman, S., \& Twite, G. (2012). An international comparison of capital structure and debt maturity choices. Journal of Financial and Quantitative Analysis, 47(1), 23-56. https://doi.org/10.1017/S0022109011000597

Ferri, M. G., Jones, W. H. (1979). Determinants of financial structure: A new methodological approach. The Journal of Finance, 34, 631-644. https://doi.org/10.1111/j.1540-6261.1979.tb02130.x

Fischer, E. O., Heinkel, R., \& Zechner, J. (1989). Dynamic capital structure choice: theory and tests. Journal of Finance, 44(1), 19-40. https://doi.org/10.1111/j.1540-6261.1989.tb02402.x

Flannery, M. J., \& Rangan, K. (2006). Partial adjustment towards target capital structures. Journal of Financial Economics, 79(3), 469-506. https://doi.org/10.1016/j.jfineco.2005.03.004

Giannetti, M. (2003). Do better institutions mitigate agency problems? Evidence from corporate finance choices. Journal of Financial and Quantitative Analysis, 38(1), 185-212. https://doi.org/10.2307/4126769

Green, H. W. (2002). Econometric Analysis. Fifth Edition. New Jersey: Prentice Hall.

Hall, G. C., Hutchinson, P. J., \& Michaelas, N. (2004). Determinants of the capital structures of European SMEs. Journal of Business Finance \& Accounting, 31(5-6), 711-728. https://doi.org/10.1111/j.0306-686X.2004.00554.x

Hayashi, F. (2000). Econometrics. Princeton: Princeton University Press.

Hovakimian, A. (2004). The Role of Target Leverage in Security Issues and Repurchases. Journal of Business, 77(4), 1041-1072. https://doi.org/10.1086/422442

Hovakimian, A., Opler, T., \& Titman, S. (2001). The debt-equity choice. Journal of Financial and Quantitative Analysis, 36(1), 1-24. https://doi.org/10.2307/2676195

International Monetary Fund. World Economics-Outlook Database. http://www.imf.org/external/pubs/ft/weo/2011/02/weodata/index.aspx

Jensen, M. (1986). Agency costs of free cash flow, corporate finance, and takeovers. American Economic Review, 76, 323-339.

Jensen, M., \& Meckling, W. (1976). Theory of the firm: Managerial behavior, agency costs and ownership structure. Journal of Financial Economics, 3, 305-360. https://doi.org/10.1016/0304-405X(76)90026-X

Kaplan, D. (2004). The Sage handbook of quantitative methodology for the social sciences. Newbury Park: Sage Publication. https://doi.org/10.4135/9781412986311

Kayo, E. K., \& Kimura, H. (2011). Hierarchical determinants of capital structure. Journal of Banking \& Finance, 35, 358-371. https://doi.org/10.1016/j.jbankfin.2010.08.015

Kline, R. B. (2011) Principles and Practice of Structural Equation Modeling. Third Edition. New York: Guilford Press.

Kovenock, D., \& Phillips, G. M. (1997). Financial structure and product market behavior: an examination of plant exit and investment. Review of Financial Studies, 10(3), 767-804. https://doi.org/10.1093/rfs/10.3.767

La Porta, R., Lopez-De-Silanes, F., Shleifer, A., \& Vishny, R. (1998). Law and finance. Journal of Political Economy, 106, 1113-1155. https://doi.org/10.1086/250042

Leary, M. T., \& Roberts, M. R. (2005). Do firms rebalance their capital structures? Journal of Finance, 60(6), 2575-2619. https://doi.org/10.1111/j.1540-6261.2005.00811.x

Lemmon, M. L., Roberts, M. R., \& Zender, J. F. (2008). Back to the beginning: Persistence and the cross-section of corporate capital structure. Journal of Finance, 63(4), 1575-1608. https://doi.org/10.1111/j.1540-6261.2008.01369.x

Lipson, M. L. (1983). The coordination role of debt. Mimeo. University of Michigan.

Lyandres, E. (2001). Strategic choices of capital structures in oligopolies: theory and evidence. Mimeo. University of Rochester.

MacKay, P. \& Phillips, G.M. (2005). How does industry affect firm financial structure? The Review of Financial Studies, 18, 1433-1466. https://doi.org/10.1093/rfs/hhi032

Mathieu, J. E., \& Taylor, S. R. (2006). Clarifying conditions and decision points for mediational type inferences in organizational behavior. Journal of Organizational Behavior, 27, 1031-1056. 
https://doi.org/10.1002/job.406

Miller, M. H. (1977). Debt and taxes. The Journal of Finance, 32(2), 261-275.

Modigliani, F., \& Miller, M. H. (1958). The cost of capital, corporation finance and the theory of investment. American Economic Review, 48, 261-297.

Myers, S. (1984). The capital structure puzzle. Journal of Finance, 39, 574-592. https://doi.org/10.1111/j.1540-6261.1984.tb03646.x

Myers, S., \& Majluf, N. (1984). Corporate financing and investment decisions when firms have information that investors do not have. Journal of Financial Economics, 13, 187-221. https://doi.org/10.1016/0304-405X(84)90023-0

Phillips, G. M. (1995). Increased debt and industry product markets: an empirical analysis. Journal of Financial Economics, 37, 189-238. https://doi.org/10.1016/0304-405X(94)00785-Y

Ranjan, R., \& Zingales, L. (1995). What do we know about capital structure? Some evidence from international data. Journal of Finance, 50, 1421-1460. https://doi.org/10.1111/j.1540-6261.1995.tb05184.x

Shyam-Sunder, L., \& Myers S. C. (1999). Testing static tradeoff against pecking order models of capital structure. Journal of Financial Economics, 51(2), 219-244. https://doi.org/10.1016/S0304-405X(98)00051-8

Simerly, R. L., \& Li, M. (2000). Environmental dynamism, capital structure and performance. A theoretical integration and an empirical test. Strategic Management Journal, 21, 31-49. https://doi.org/10.1002/(SICI)1097-0266(200001)21:1<31::AID-SMJ76>3.0.CO;2-T

Smith, D., \& Smith, K. L. (2004). Structural equation modelling in management accounting research: critical analysis and opportunities. Journal of Accounting Literature, 23, 49-86.

Spamann, H. (2010). The "Antidirector Rights Index" Revisited. The Review of Financial Studies, 23(2). 467-486. https://doi.org/10.1093/rfs/hhp067

Stulz, R., \& Johnson, H. (1985). An Analysis of Secured Debt. Journal of Financial Economics, 14, 501-521. https://doi.org/10.1016/0304-405X(85)90024-8

Venanzi, D. (2010). Il puzzle della struttura finanziaria. Milan: Pearson Italia.

Venanzi, D. (2017). How Country Affects the Capital Structure Choice: Literature Review and Criticism. International Journal of Economics and Finance, 9(4). https://doi.org/10.5539/ijef.v9n4p1

Watson, J. (2010). SME Performance. Separating Myth from Reality. Cheltenham: Edward Elgar Publishing. https://doi.org/10.4337/9781849805643

Welch, I. (2011). Two common problems in capital structure research: the financial-debt-to-asset ratio and issuing activity versus leverage changes. International Review of Finance, 11(1), 1-17. https://doi.org/10.1111/j.1468-2443.2010.01125.x

World Bank, World Development Indicators, http://data.worldbank.org/indicator/all

\section{Copyrights}

Copyright for this article is retained by the author(s), with first publication rights granted to the journal.

This is an open-access article distributed under the terms and conditions of the Creative Commons Attribution license (http://creativecommons.org/licenses/by/4.0/). 